\title{
Furofuranone Lignans from Leucophyllum ambiguum
}

María Y. Rios, ${ }^{*} \uparrow$ Yordin D. Ocampo-Acuña,${ }^{\dagger}$ M. Ángeles Ramírez-Cisneros,${ }^{\dagger}$ and María E. Salazar-Rios ${ }^{\sharp}$

†Centro de Investigaciones Químicas, IICBA, Universidad Autónoma del Estado de Morelos, Cuernavaca 62209, Morelos, México

§Facultad de Medicina, Universidad Autónoma del Estado de Morelos, Cuernavaca 62350, Morelos, México

\section{SUPPORTING INFORMATION}




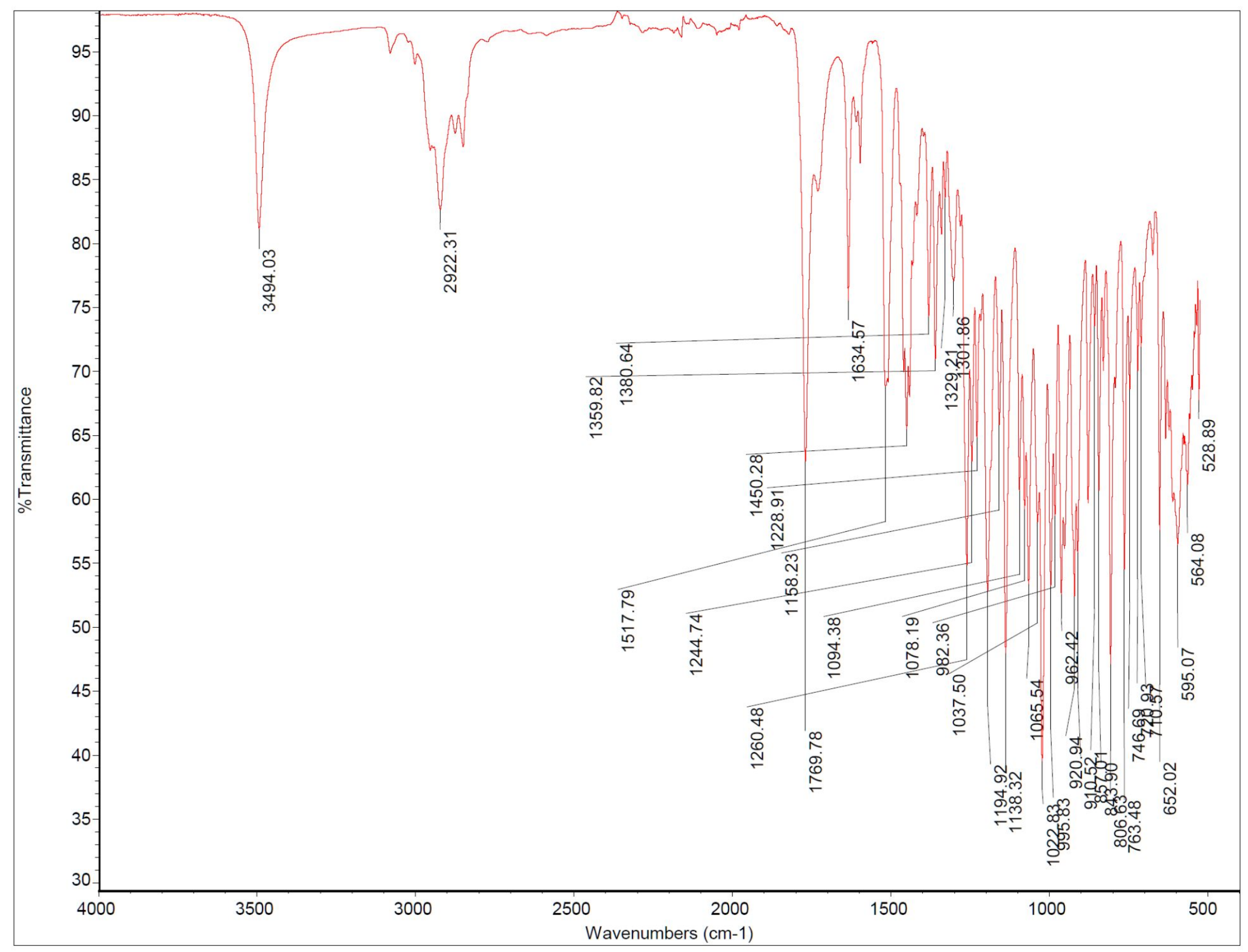

Figure S1. IR $\left(\mathrm{CDCl}_{3}\right)$ of ciquitin A (1) 


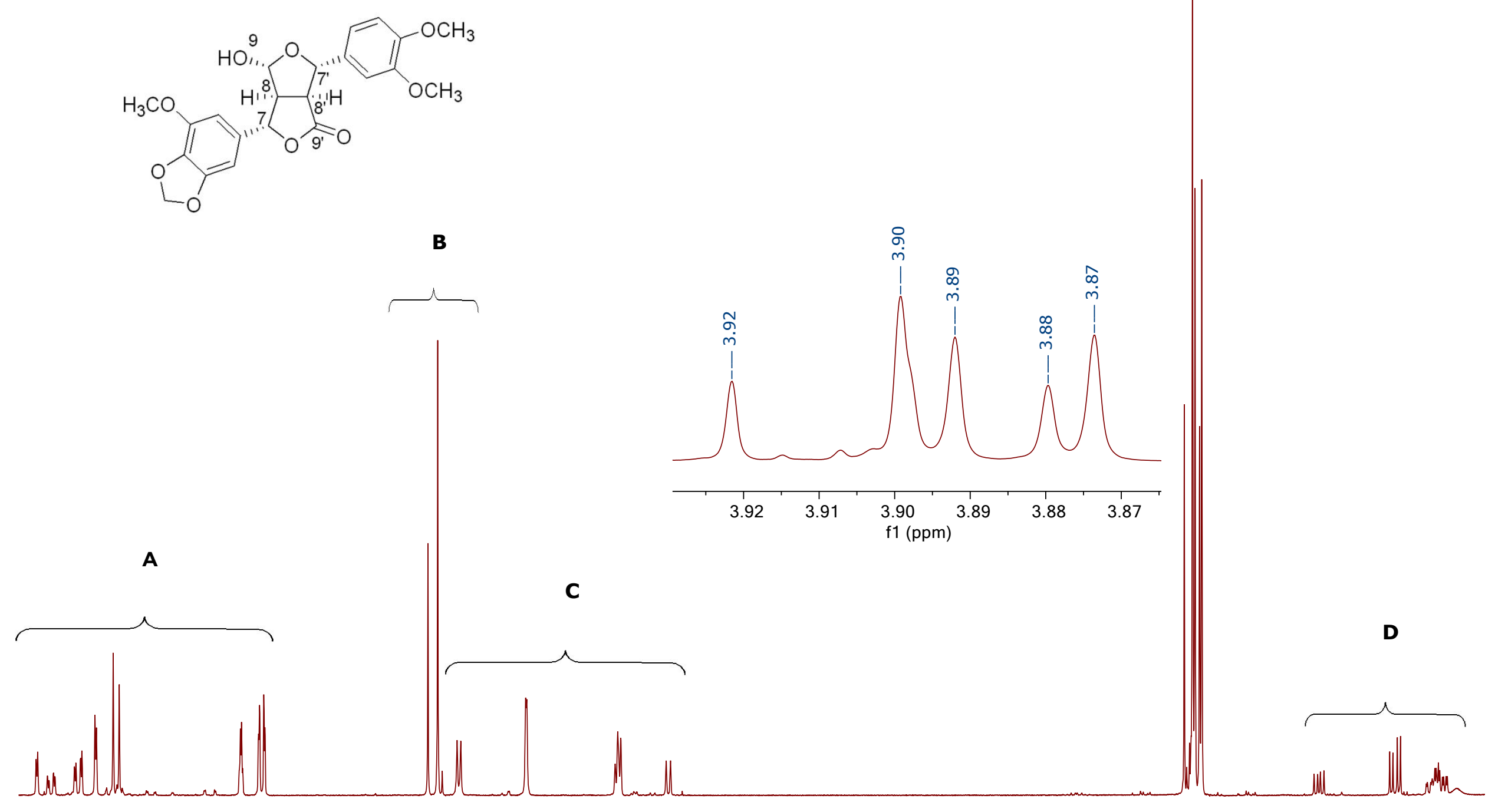

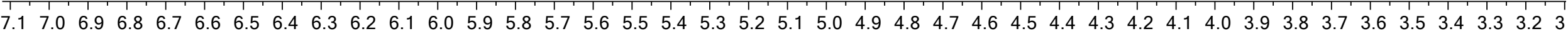
$\mathrm{f} 1(\mathrm{ppm})$

Figure S2. ${ }^{1} \mathrm{HNMR}\left(\mathrm{CDCl}_{3}, 400 \mathrm{MHz}\right)$ of ciquitin A (1) 


\section{REGION B}

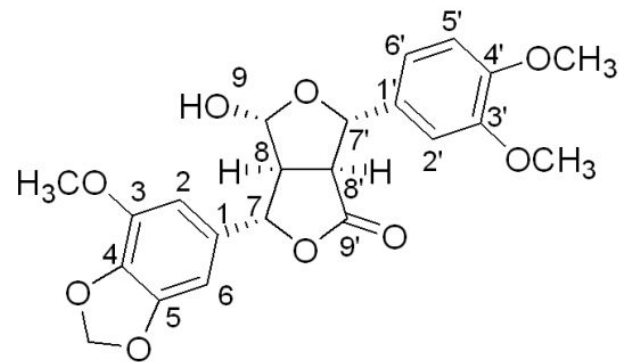

REGION A

\begin{tabular}{|c|c|}
\hline $\begin{array}{c}\text { H-2' (dd) } \\
7.03\end{array}$ & $\begin{array}{c}H-2{ }^{\prime}(\mathrm{dd}) \\
6.96 \\
\mathrm{~J}(8.30,2.00)\end{array}$ \\
$\mathrm{J}(8.30,2.00)$ \\
\hline $\begin{array}{c}H-6{ }^{\prime}(\mathrm{d}) \\
7.07\end{array}$ \\
$\mathrm{~J}(2.00)$ \\
\hline
\end{tabular}

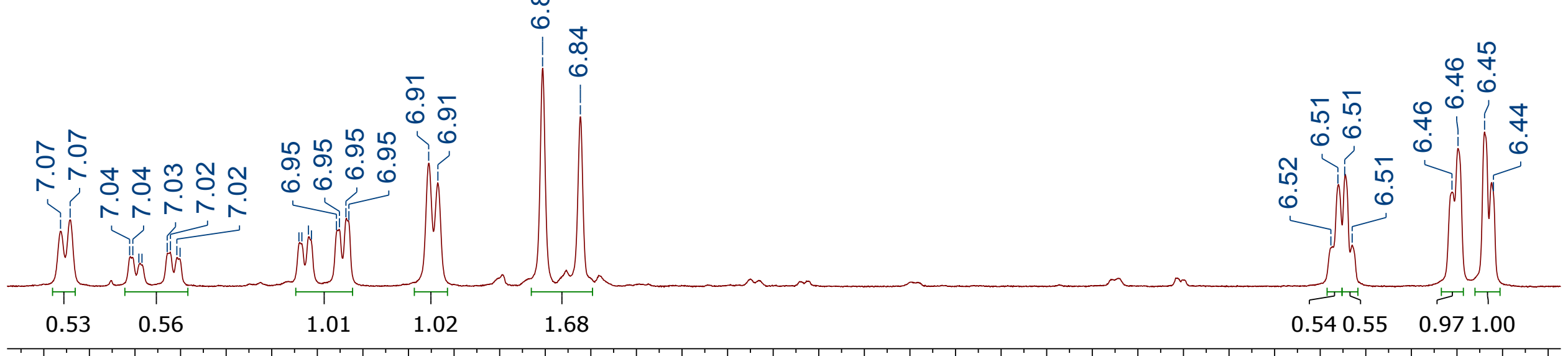

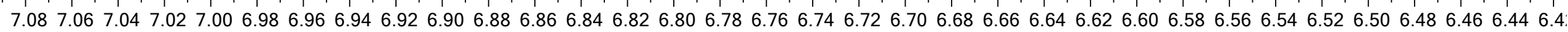
f1 (ppm)

\begin{tabular}{|c|c|}
\hline$H-6(d)$ & $H-2(d)$ \\
6.51 & 6.46 \\
$J(1.51)$ & $J(1.95)$ \\
\hline$H-2(d)$ & $H-6(d)$ \\
6.51 & 6.45 \\
$J(1.51)$ & $J(1.95)$ \\
\hline
\end{tabular}

6.0056 .0005 .9955 .9905 .9855 .9805 .9755 .9705 .9655 .960

f1 (ppm)

\begin{tabular}{|c|}
\hline$H-3^{\prime}(d)$ \\
6.85 \\
$J(8.30)$ \\
\hline$H-3^{\prime}(d)$ \\
6.85 \\
$J(8.30)$ \\
\hline
\end{tabular}

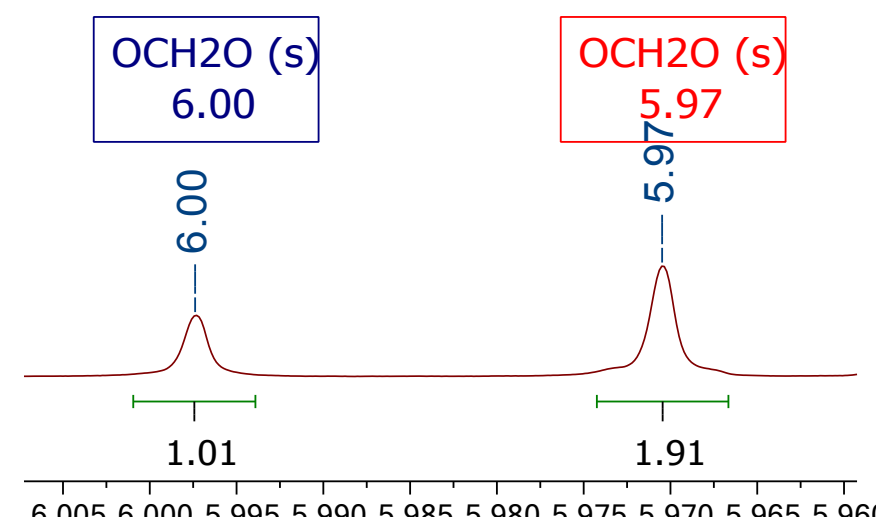



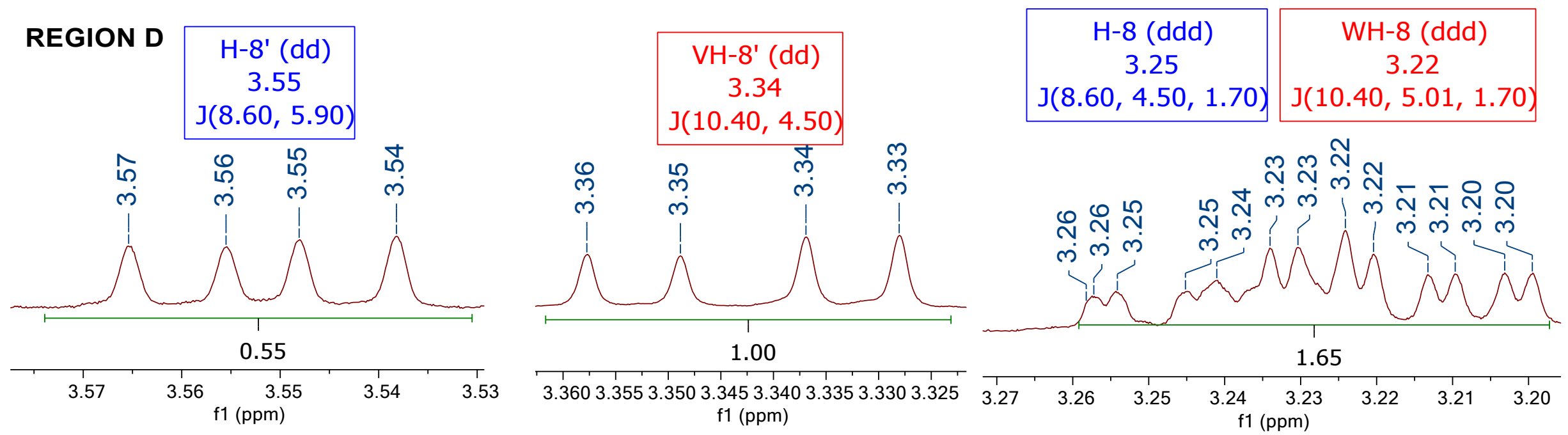

\section{REGION C}
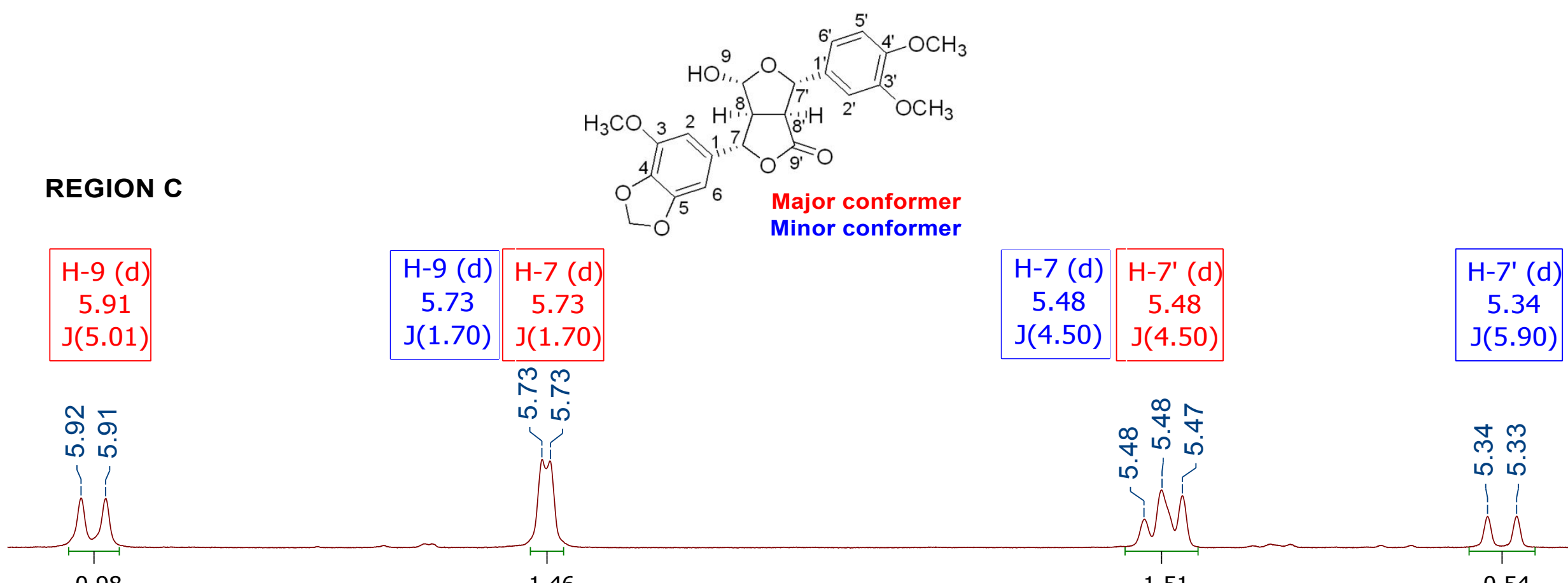

ما

ชั

"ก

)

مَ

ले ल

1)

"ก

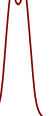

0.98

1.46

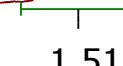

0.54

$5.90 \quad 5.85$

5.80

5.75

5.70

5.65

f1 (ppm)

Figure S4. ${ }^{1} \mathrm{HNMR}\left(\mathrm{CDCl}_{3}, 400 \mathrm{MHz}\right)$ ampliation of $\delta 5.3$ to 5.9 and $\delta 3.1$ to 3.6 of ciquitin $\mathrm{A}(\mathbf{1})$ 
13C NMR (175 MHz, CDC1) $\delta 176.99,176.08,149.74,149.74,149.44,149.41,149.10$, $149.08,144.16,144.06,135.93,135.45,134.64,133.97,133.09,133.03,118.39,117.93$, $111.41,111.20,109.31,108.76,105.63,105.27,103.02,102.13,102.04,99.90,99.45$, $98.41,85.13,82.71,81.16,79.75,58.66,57.10,57.07,56.22,56.20,54.00,52.61,51.70$
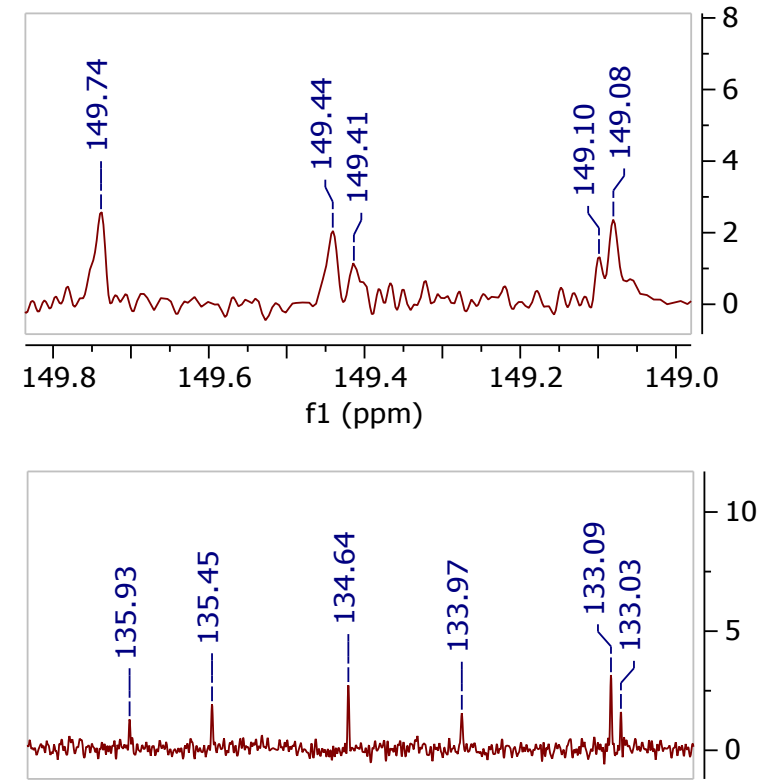

136.5136 .0135 .5135 .0134 .5134 .0133 .5133 .0 f1 (ppm)

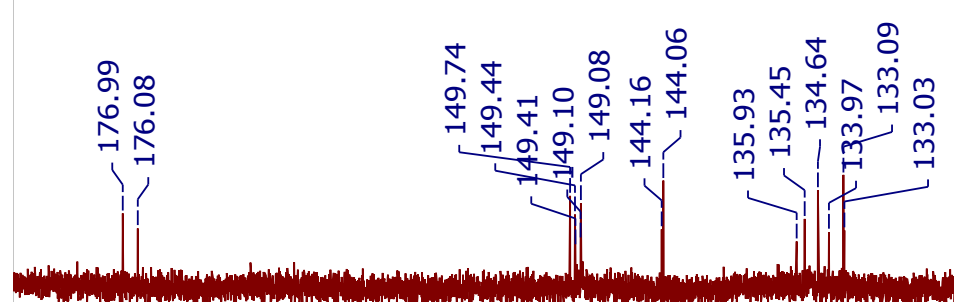

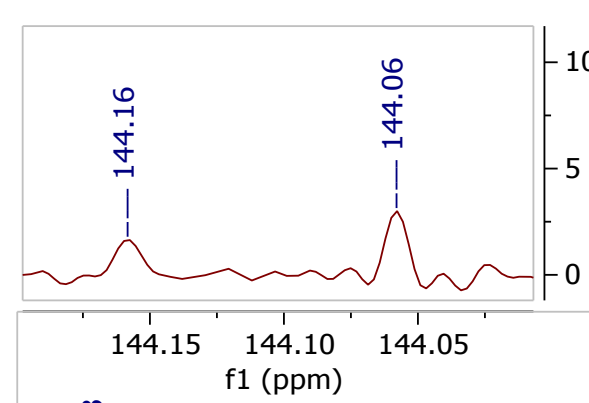
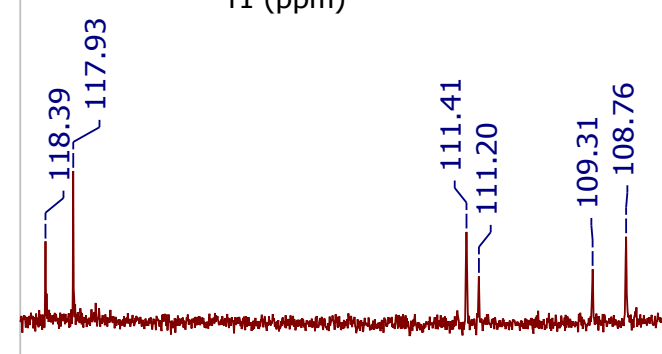

118117116115114113112111110109108107 f1 (ppm)
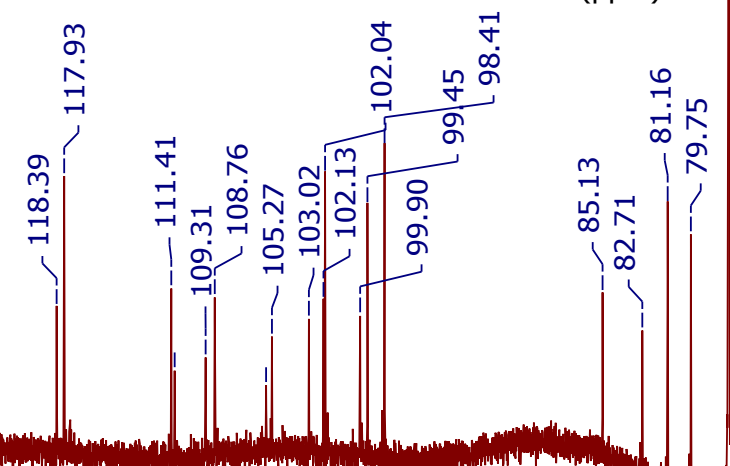

ம்

$1 \infty$

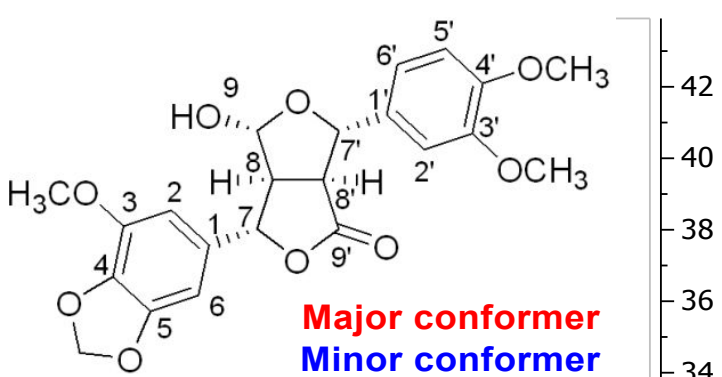

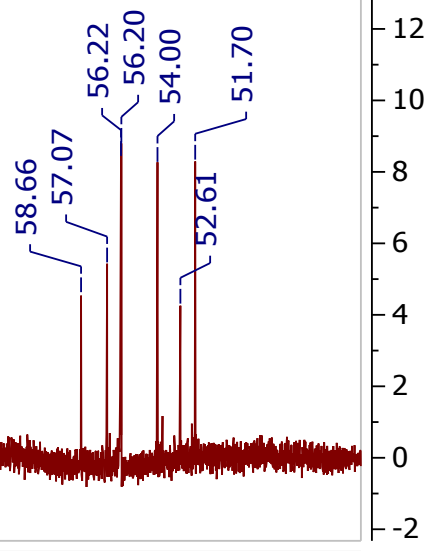

$\begin{array}{lllllllllllllll}180 & 175 & 170 & 165 & 160 & 155 & 150 & 145 & 140 & 135 & 130 & 125 & 120 & 115 & 110\end{array}$

Figure S5. ${ }^{13} \mathrm{CNMR}\left(\mathrm{CDCl}_{3}, 175 \mathrm{MHz}\right)$ of ciquitin A (1) 


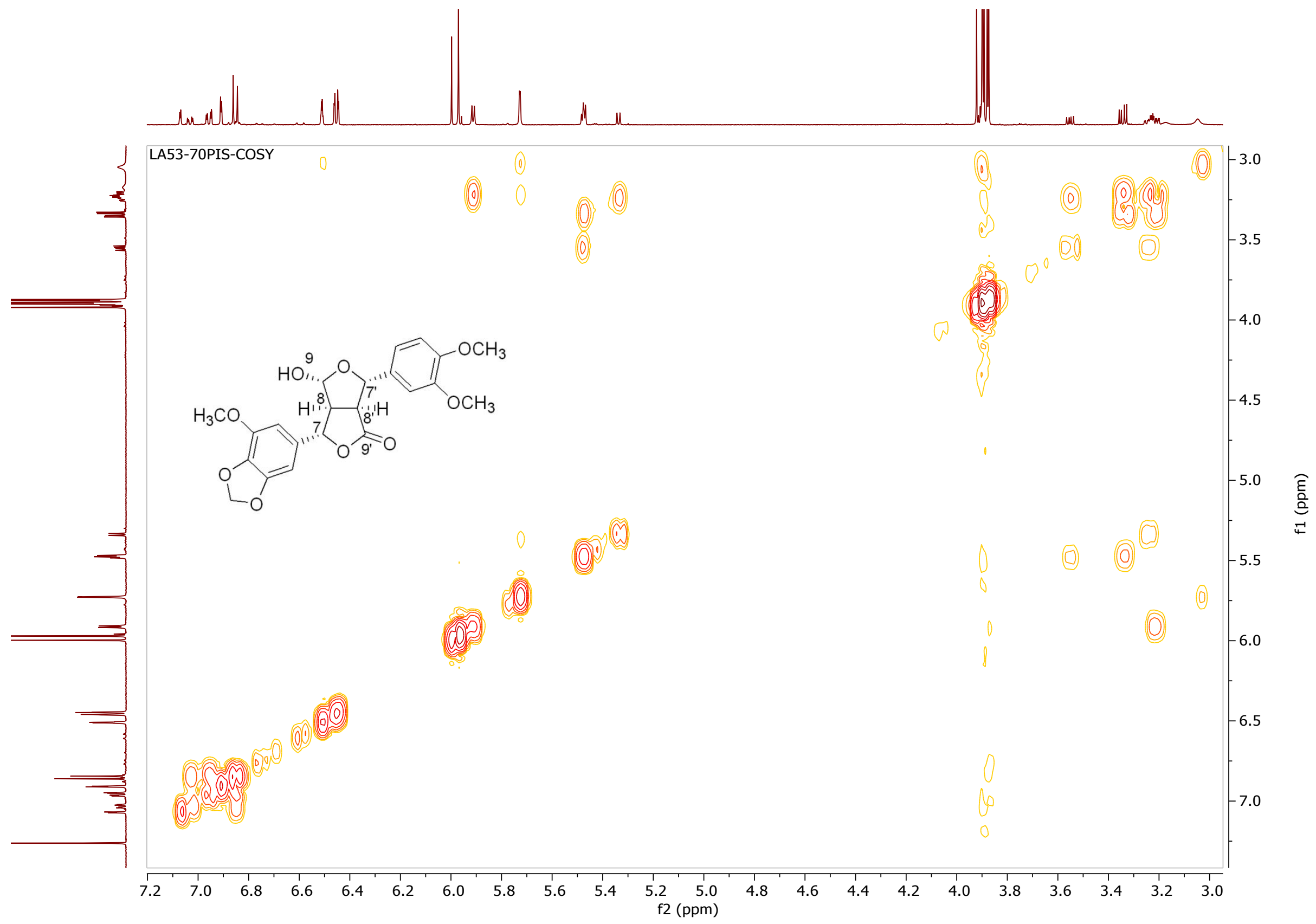

Figure S6. $\mathrm{COSY}\left(\mathrm{CDCl}_{3}, 400 \mathrm{MHz}\right)$ of ciquitin A (1) 


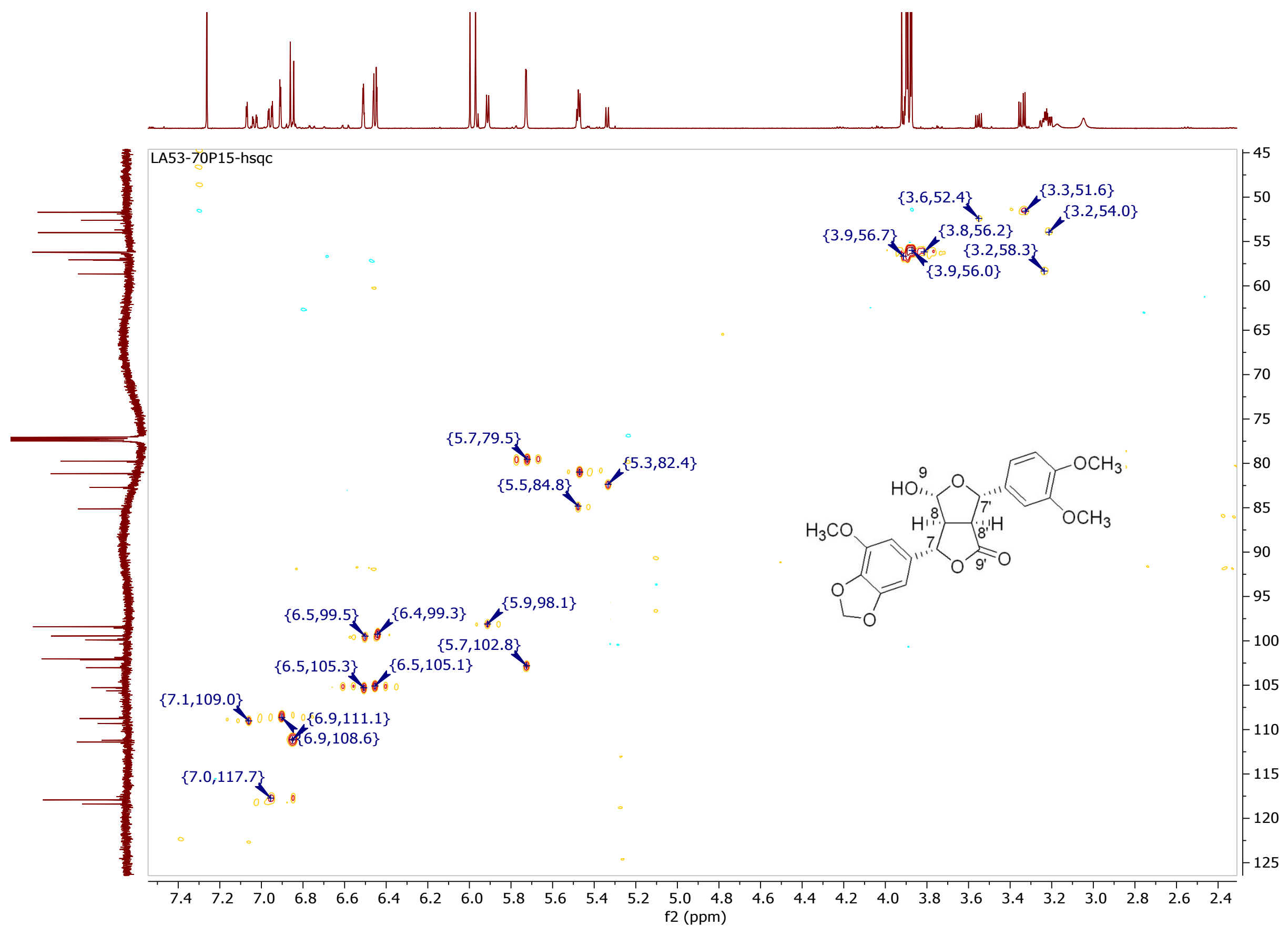

Figure S7. HSQC (CDCl, $400 \mathrm{MHz})$ of ciquitin A (1) 


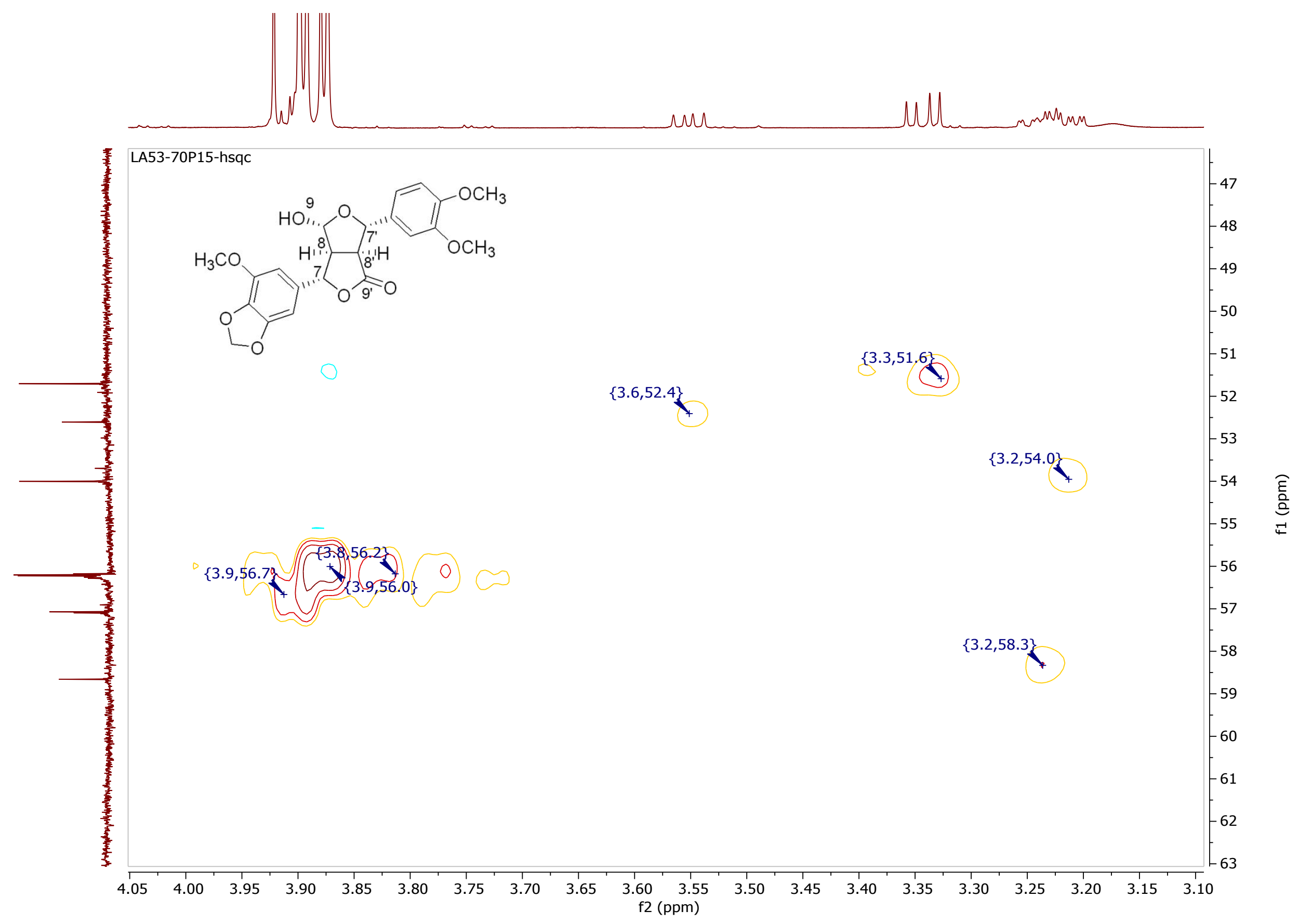

Figure S8. HSQC ( $\left.\mathrm{CDCl}_{3}, 400 \mathrm{MHz}\right)$ of ciquitin A (1) 


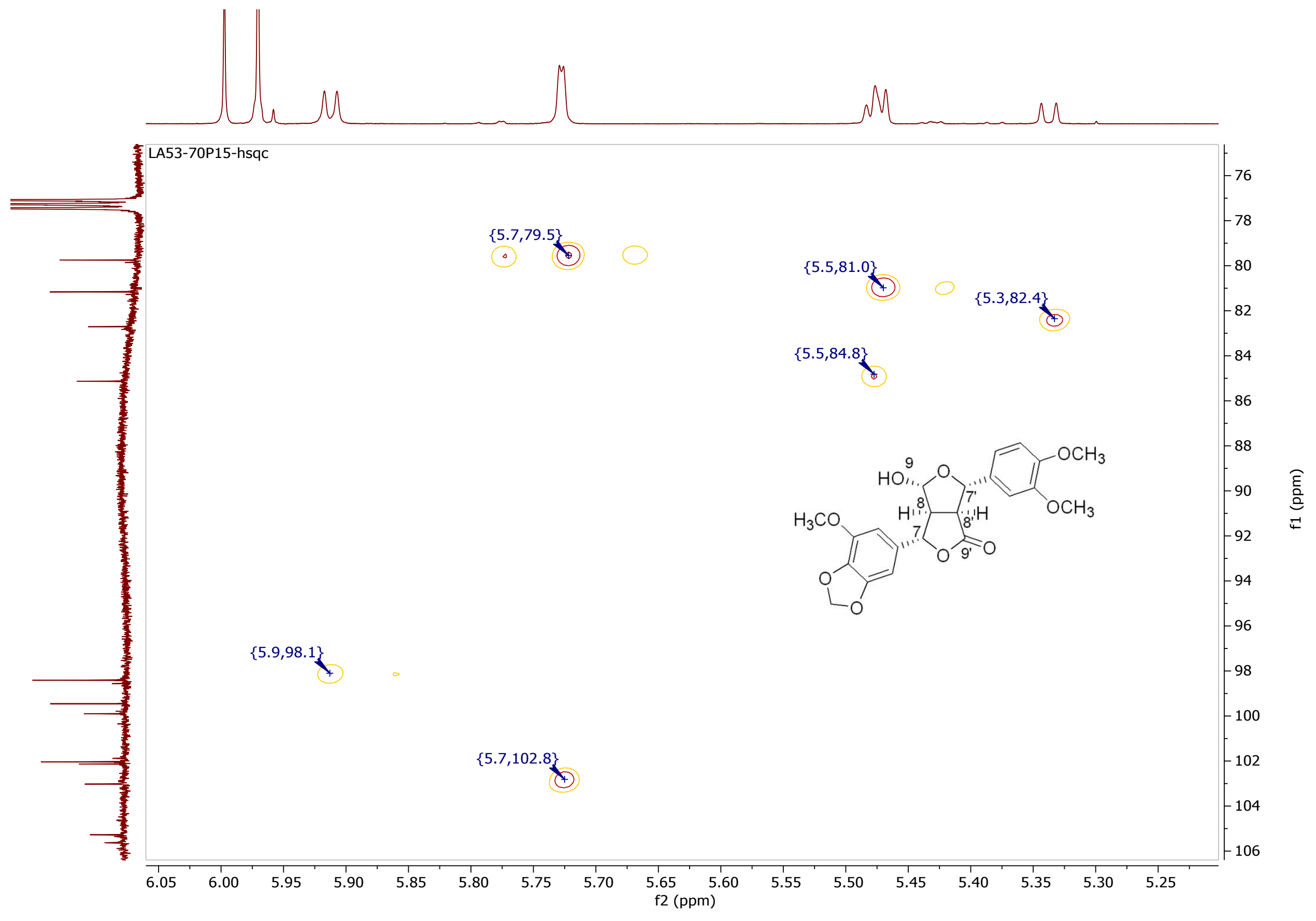

Figure S9. HSQC ( $\left.\mathrm{CDCl}_{3}, 400 \mathrm{MHz}\right)$ of ciquitin A (1) 


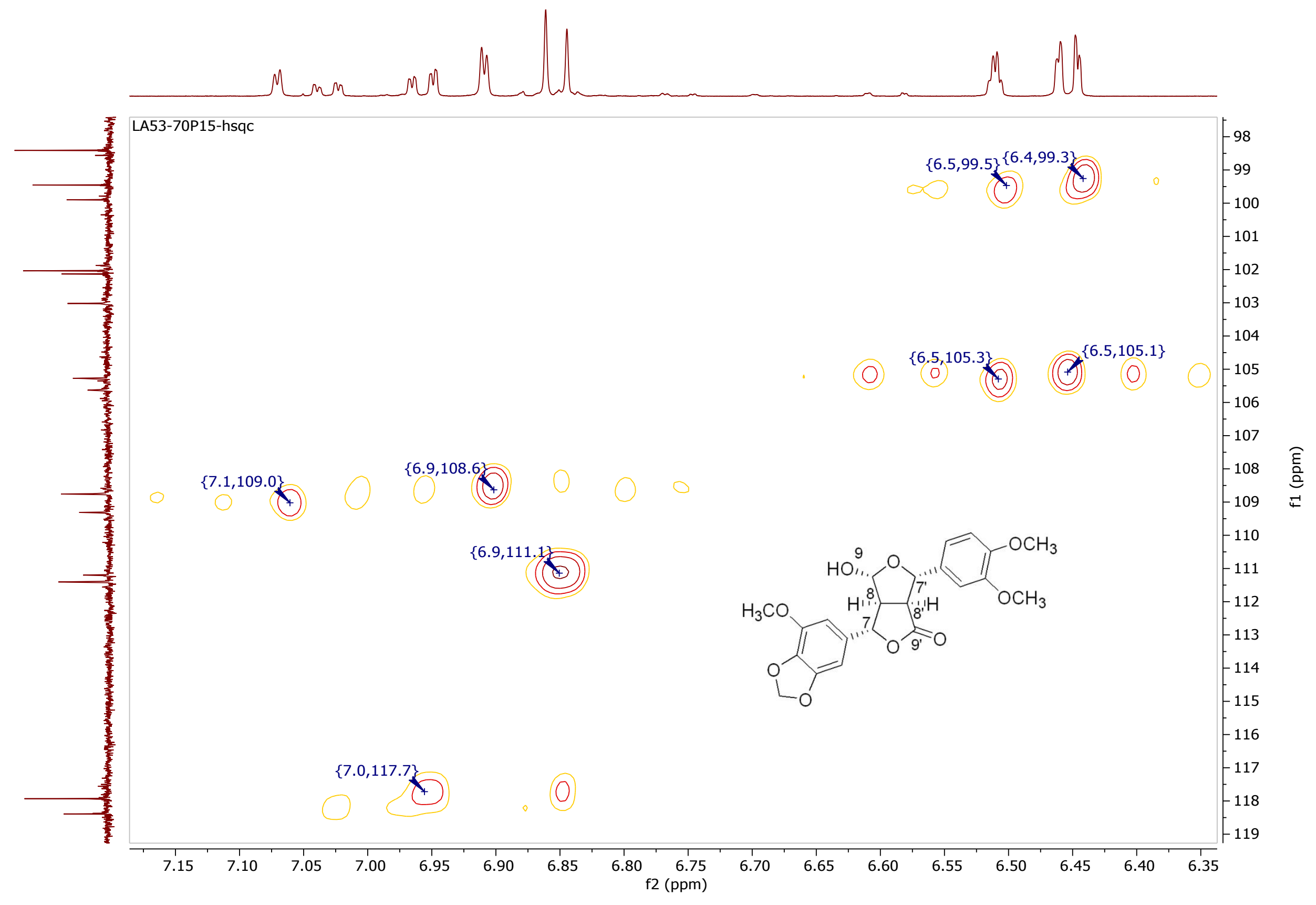

Figure S10. HSQC $\left(\mathrm{CDCl}_{3}, 400 \mathrm{MHz}\right)$ of ciquitin A (1) 


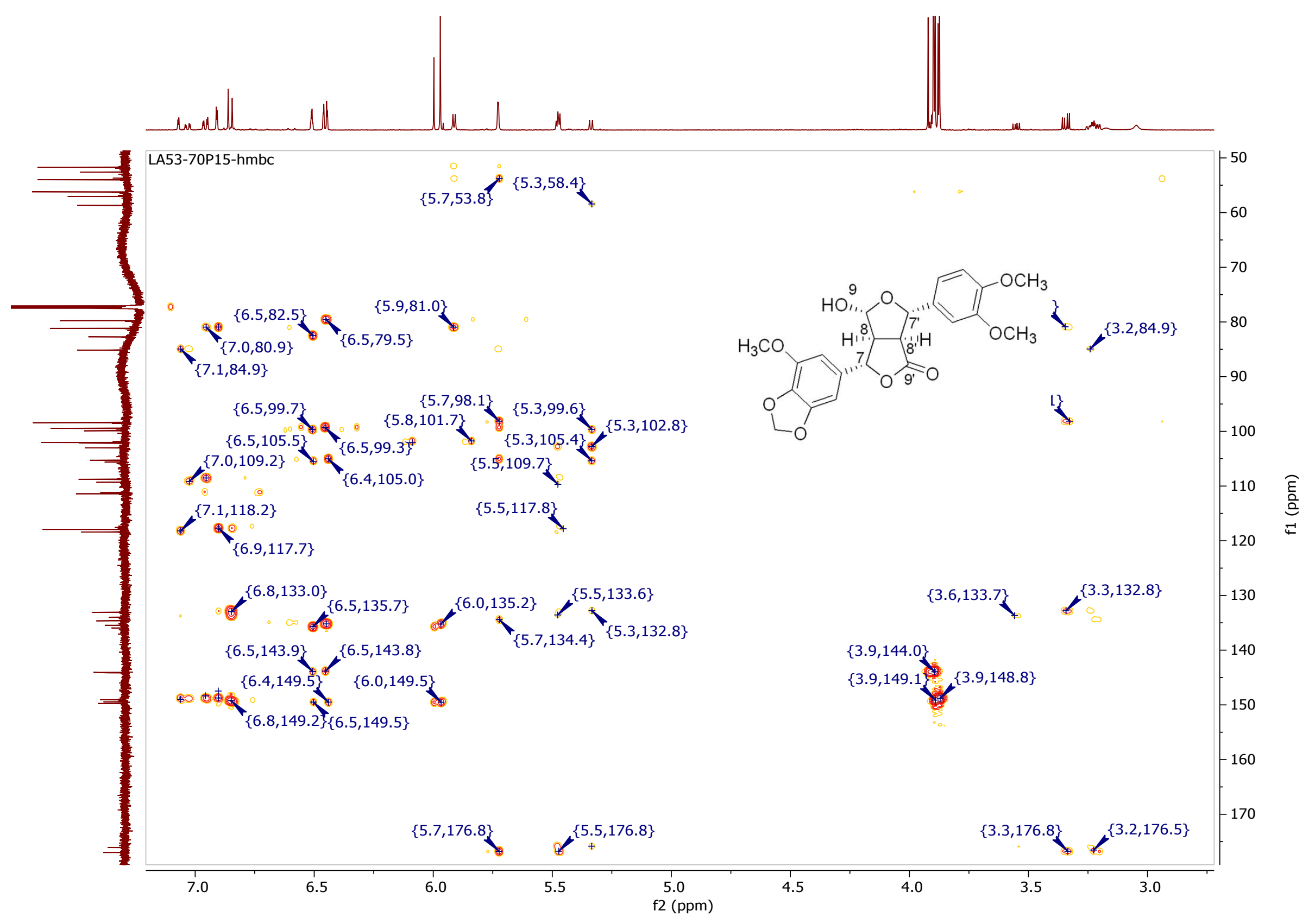

Figure S11. $\mathrm{HMBC}\left(\mathrm{CDCl}_{3}, 400 \mathrm{MHz}\right)$ of ciquitin A (1) 


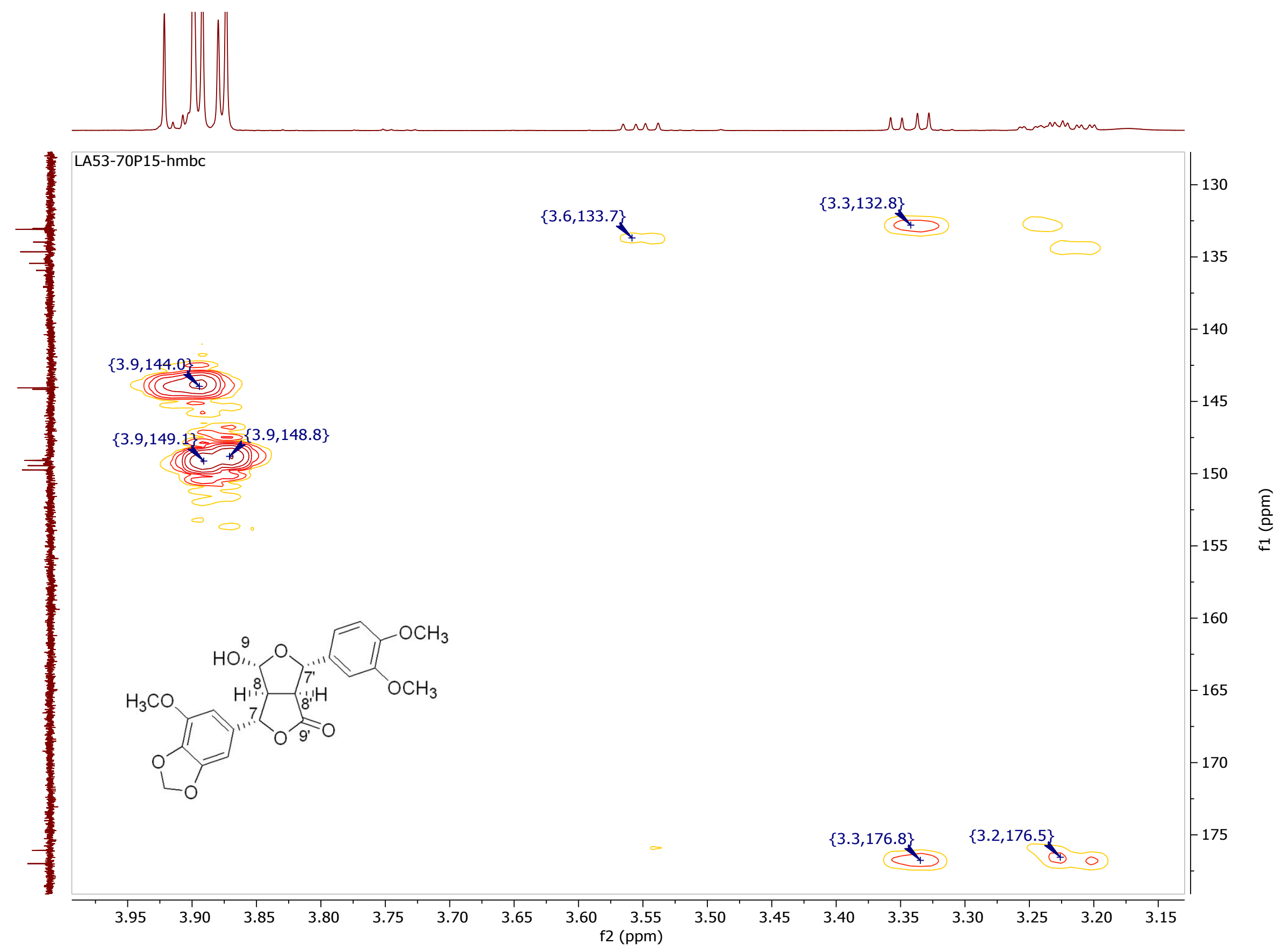

Figure $\mathbf{S 1 2}$. $\mathrm{HMBC}\left(\mathrm{CDCl}_{3}, 400 \mathrm{MHz}\right)$ of ciquitin A (1) 


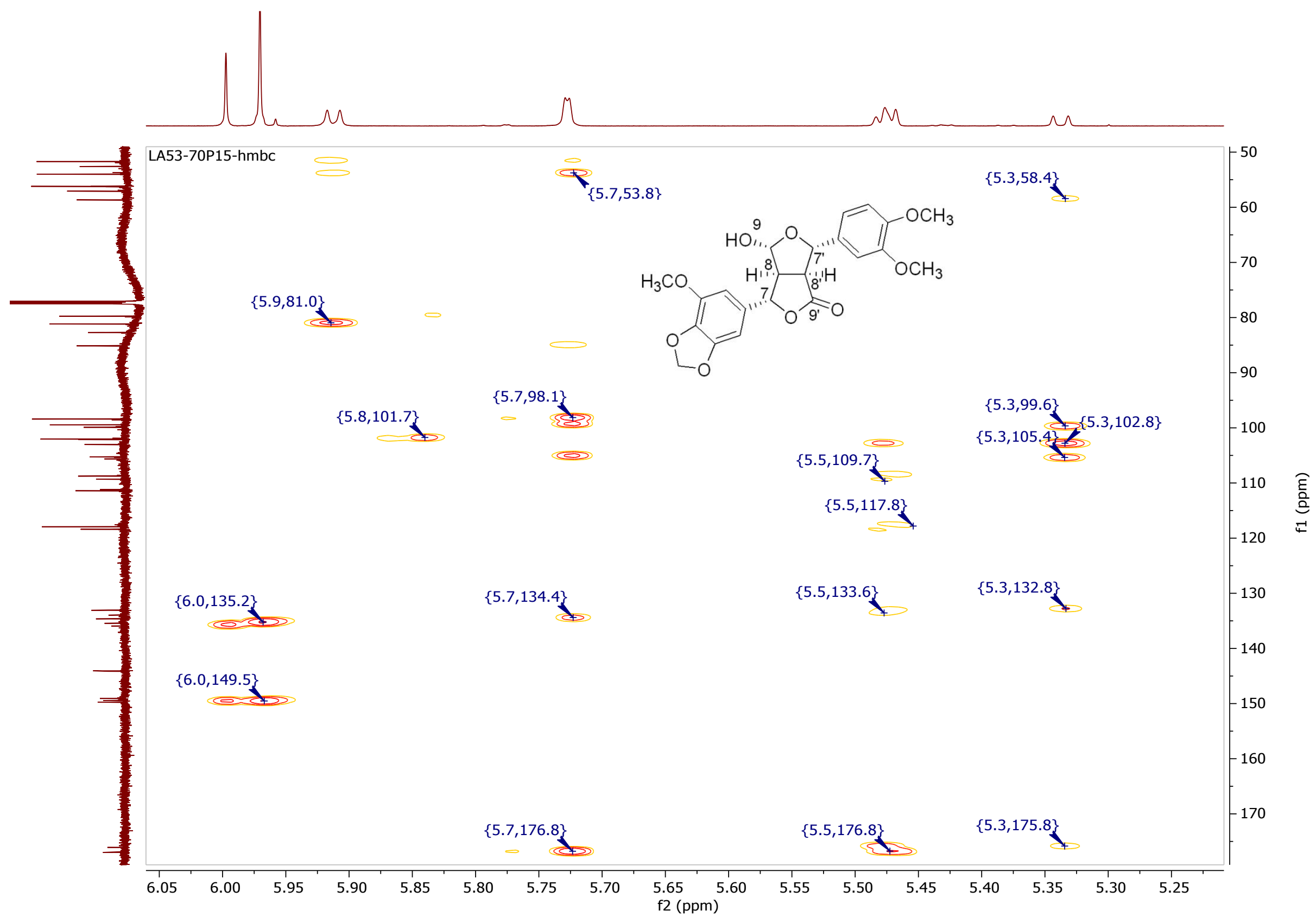

Figure S13. $\mathrm{HMBC}\left(\mathrm{CDCl}_{3}, 400 \mathrm{MHz}\right)$ of ciquitin A (1) 


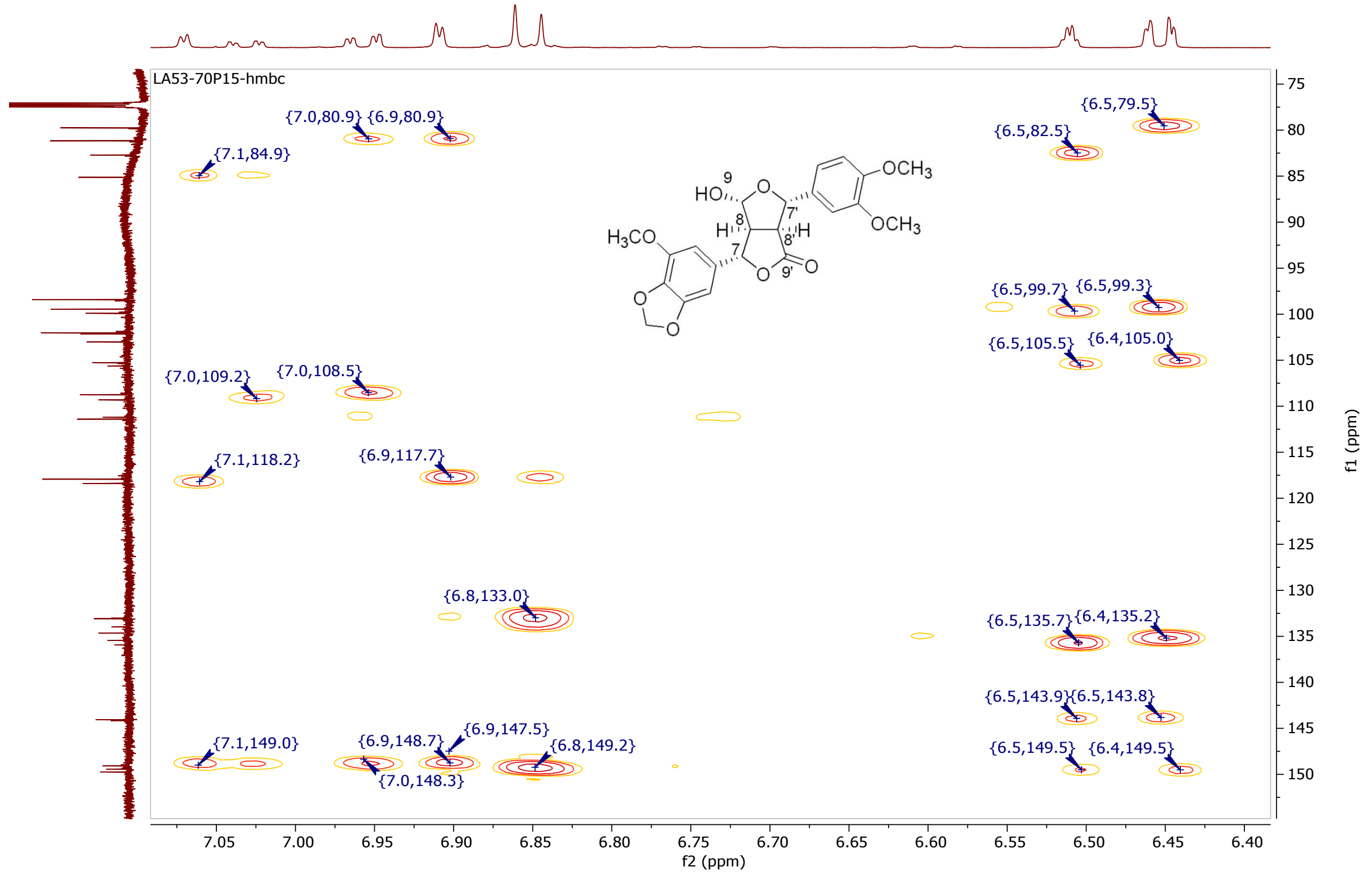

Figure S14. $\mathrm{HMBC}\left(\mathrm{CDCl}_{3}, 400 \mathrm{MHz}\right)$ of ciquitin A (1) 


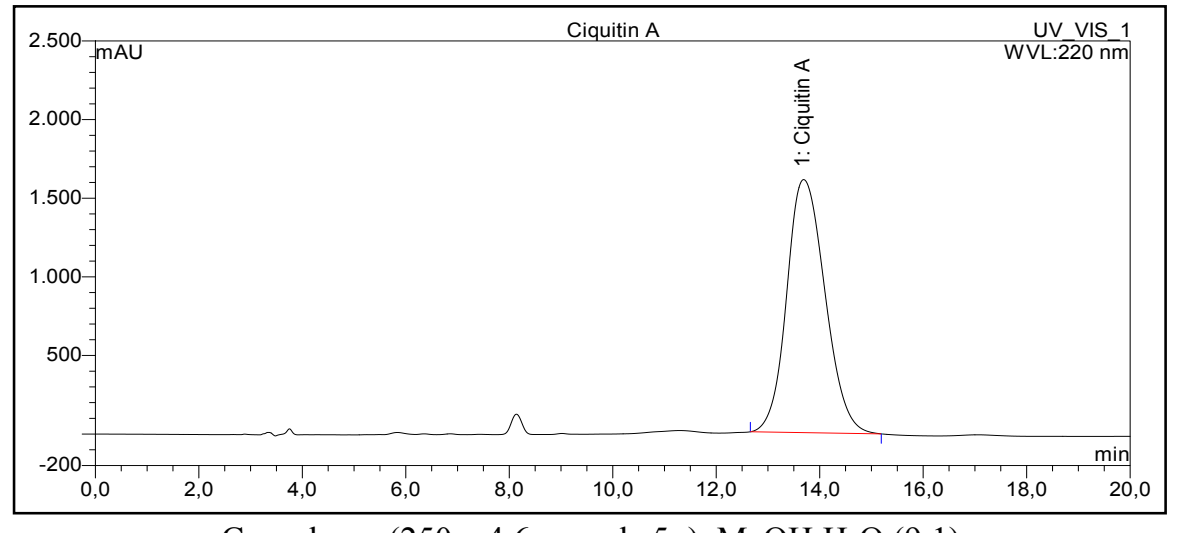

$\mathrm{C}_{18}$ column $(250 \times 4.6 \mathrm{~mm}$, de $5 \mu), \mathrm{MeOH}: \mathrm{H}_{2} \mathrm{O}(9: 1)$

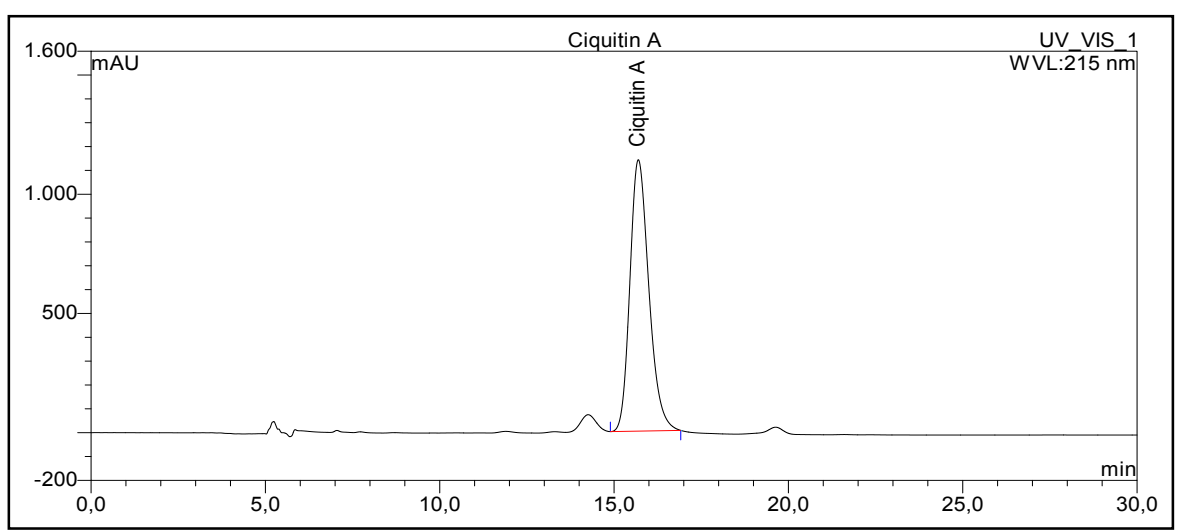

Phenomenex Lux cellulose-1 chiral column $(150 \times 4.6 \mathrm{~cm}, 3 \mu)$, Isopropanol: $\mathrm{H}_{2} \mathrm{O}(7: 3)$
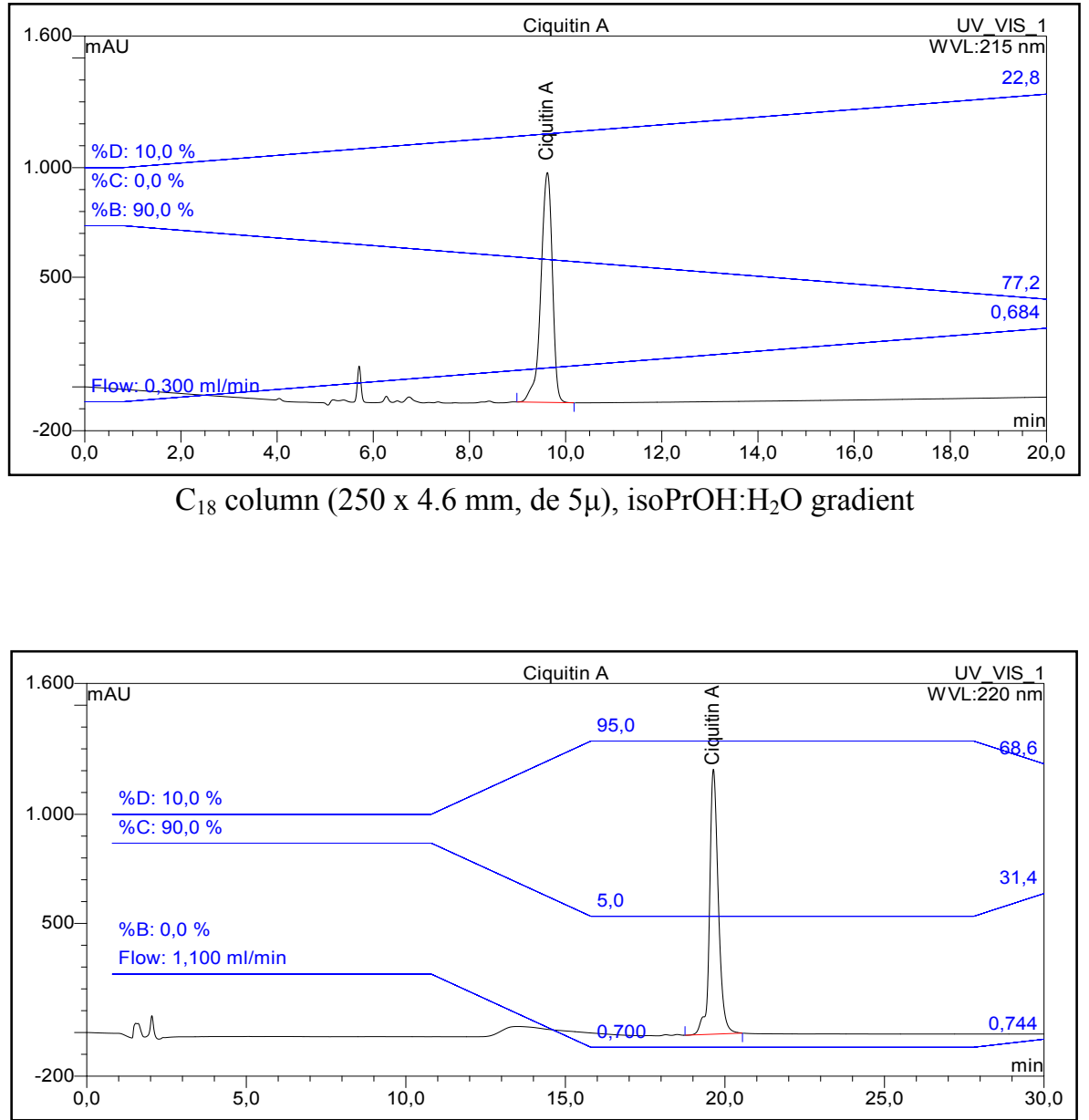

Phenomenex Lux cellulose-1 chiral column $(150 \times 4.6 \mathrm{~cm}, 3 \mu)$, Isopropanol: $\mathrm{H}_{2} \mathrm{O}$ gradient

Figure S15. HPLC analysis of ciquitin A (1) 


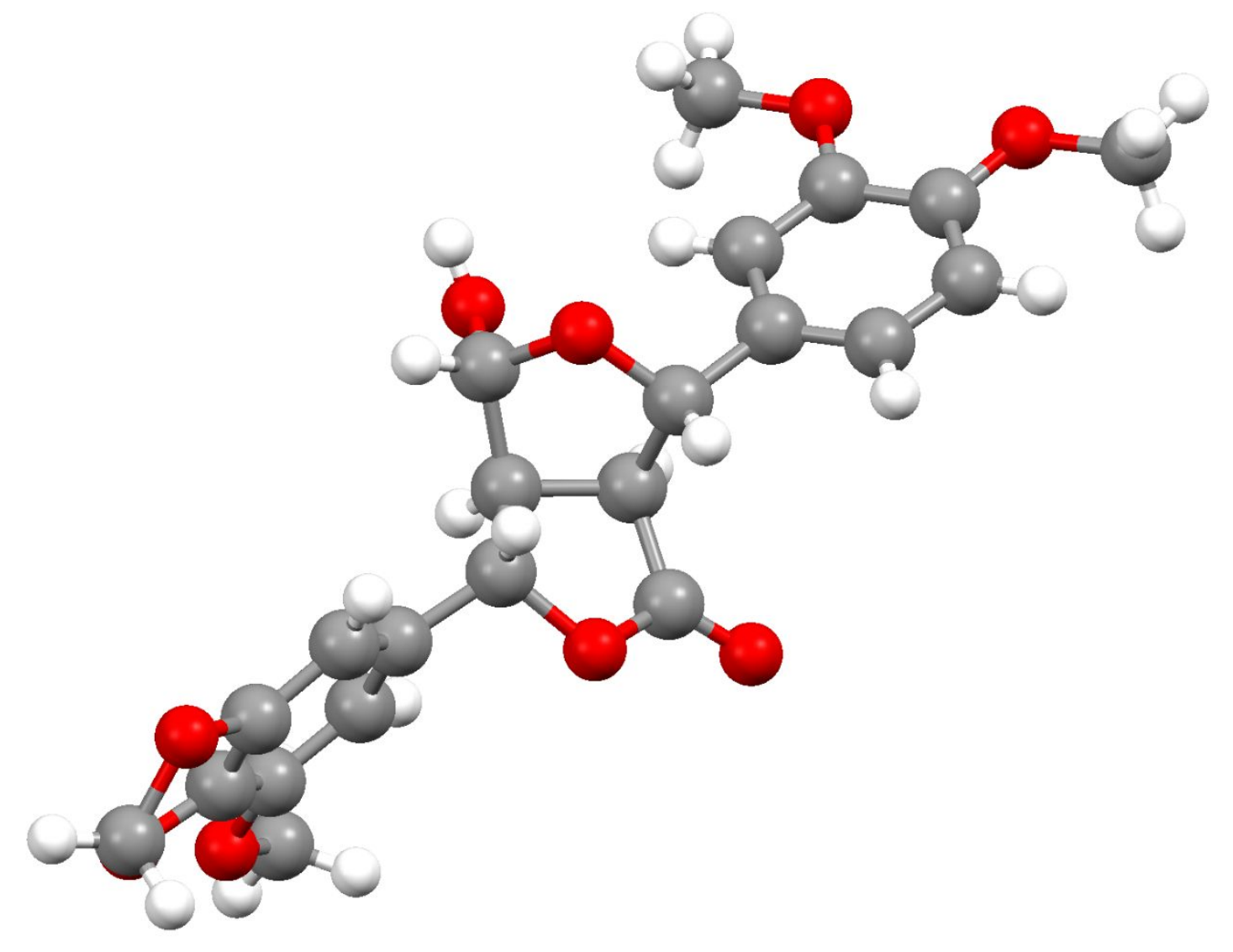

Figure S16. X-Ray ORTEP diagram of ciquitin A (1, CCDC 1937984) 
Table S1. Crystal data and structure refinement for cu_ciquitin A (1)_0m.

Identification code

Empirical formula

Formula weight

Temperature

Wavelength

Crystal system

Space group

Unit cell dimensions

\section{Volume}

Z

Density (calculated)

Absorption coefficient

$\mathrm{F}(000)$

Crystal size

Theta range for data collection

Index ranges

Reflections collected

Independent reflections

Completeness to theta $=67.679^{\circ}$

Absorption correction

Refinement method

Data / restraints / parameters

Goodness-of-fit on $\mathrm{F}^{2}$

Final $\mathrm{R}$ indices [I $>2$ sigma(I)]

$\mathrm{R}$ indices (all data)

Absolute structure parameter

Extinction coefficient

Largest diff. peak and hole
cu_250RGY18_0m

C22 H22 O9

430.39

$100(2) \mathrm{K}$

$1.54178 \AA$

Orthorhombic

$\mathrm{P} 22_{1} 2_{1}$

$a=6.52327(7) \AA$

$\alpha=90^{\circ}$.

$\mathrm{b}=12.13824(14) \AA$

$\beta=90^{\circ}$.

$\mathrm{c}=25.2248(3) \AA$

$\gamma=90^{\circ}$.

1997.33(4) $\AA^{3}$

$1.431 \mathrm{Mg} / \mathrm{m}^{3}$

$0.947 \mathrm{~mm}^{-1}$

904

$0.236 \times 0.180 \times 0.096 \mathrm{~mm}^{3}$

3.504 to $69.133^{\circ}$.

$-7<=\mathrm{h}<=7,-14<=\mathrm{k}<=14,-30<=\mathrm{l}<=30$

20548

$3716[\mathrm{R}($ int $)=0.0265]$

$99.9 \%$

None

Full-matrix least-squares on $\mathrm{F}^{2}$

3716 / 1 / 286

1.089

$\mathrm{R} 1=0.0266, \mathrm{wR} 2=0.0701$

$\mathrm{R} 1=0.0266, \mathrm{wR} 2=0.0702$

0.05(3)

$\mathrm{n} / \mathrm{a}$

0.309 and -0.182 e. $\AA^{-3}$ 


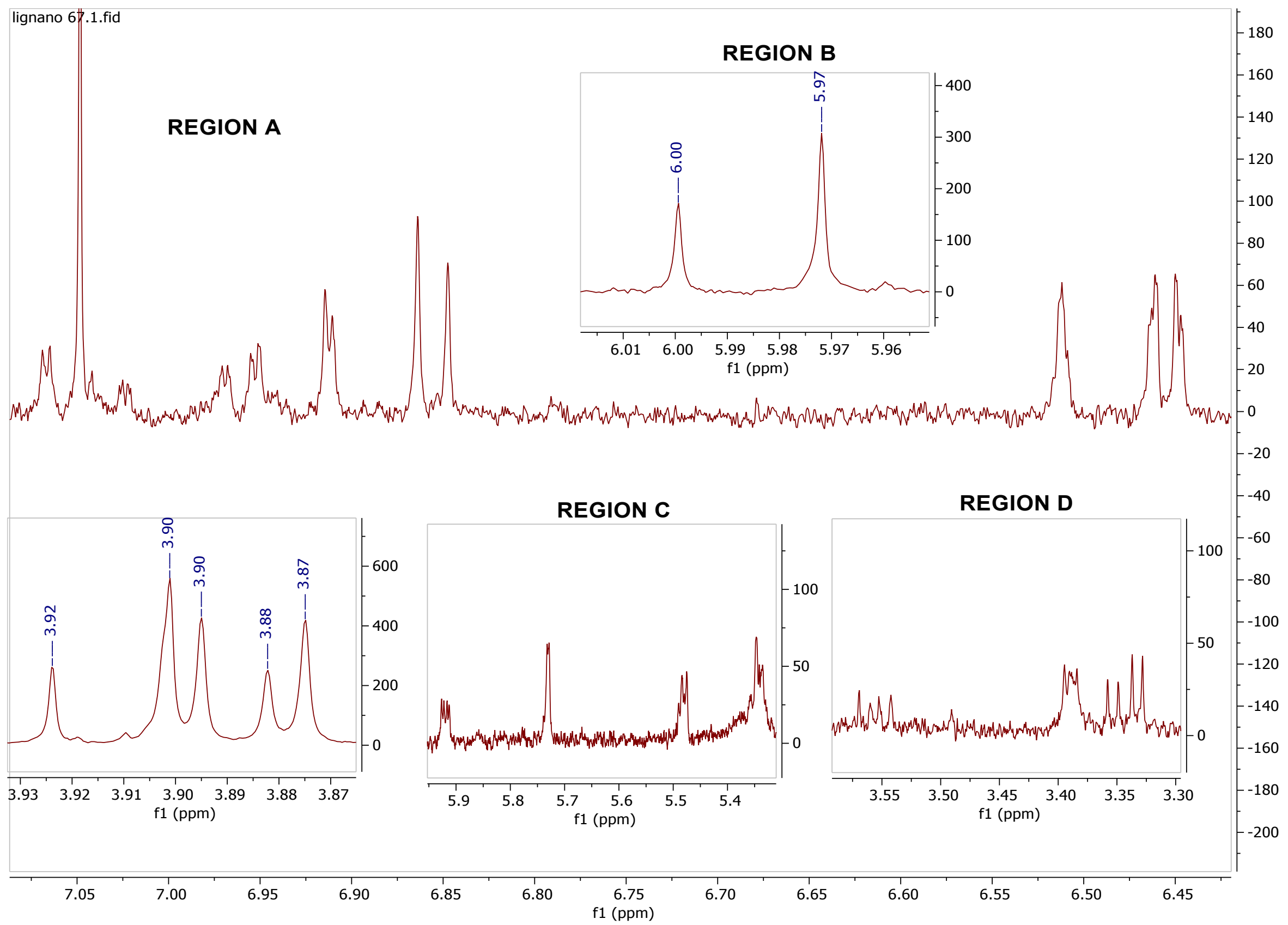

Figure S17. ${ }^{1} \mathrm{HNMR}\left(\mathrm{CDCl}_{3}, 700 \mathrm{MHz}\right)$ of X-ray analyzed crystals of pure ciquitin A (1) 


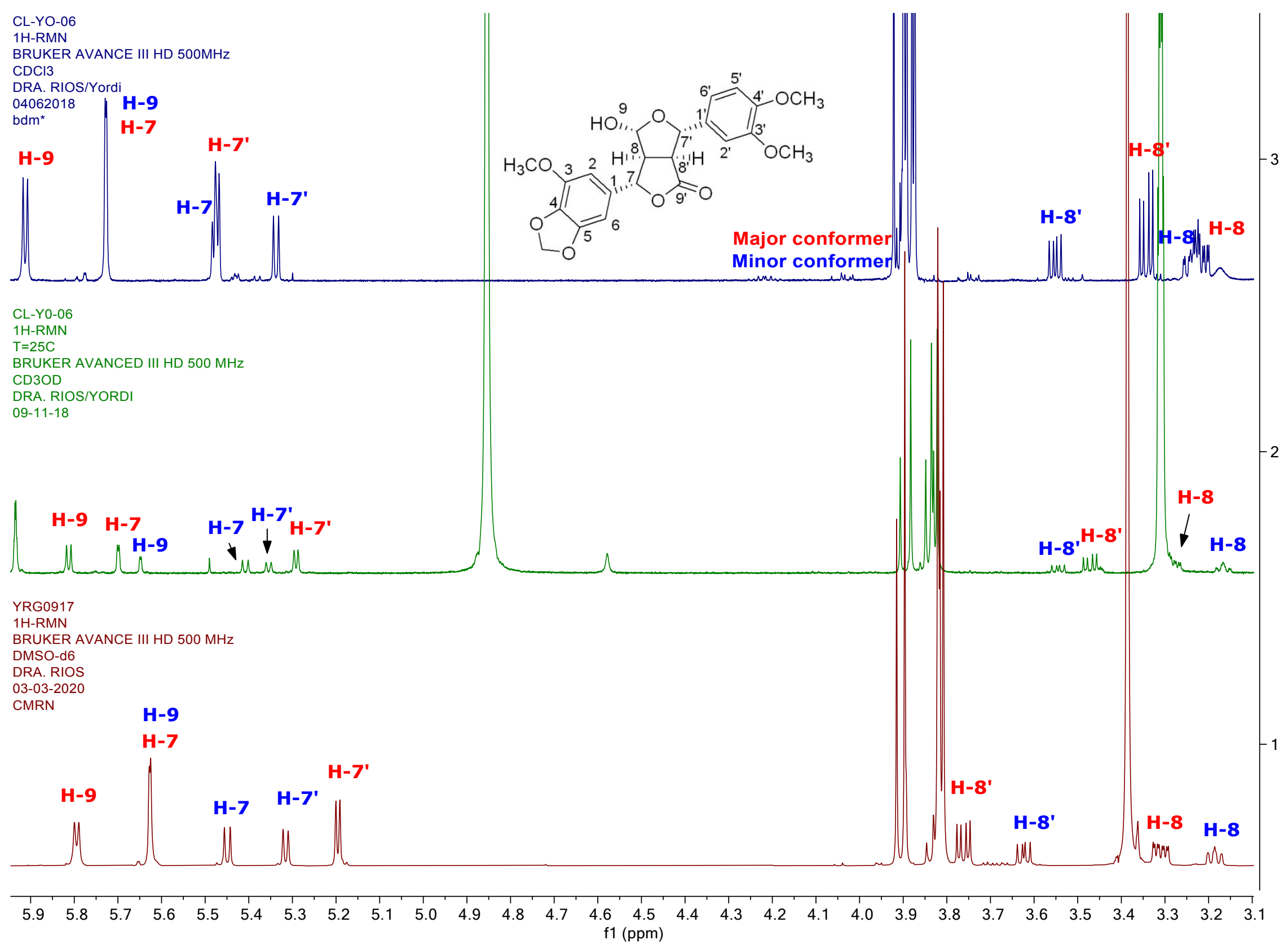

Figure S18. Comparison of ${ }^{1} \mathrm{HNMR}$ spectra of ciquitin $\mathrm{A}$ (1) in $\mathrm{CDCl}_{3}, \mathrm{MeOD}$ and DMSO (500 MHz). 


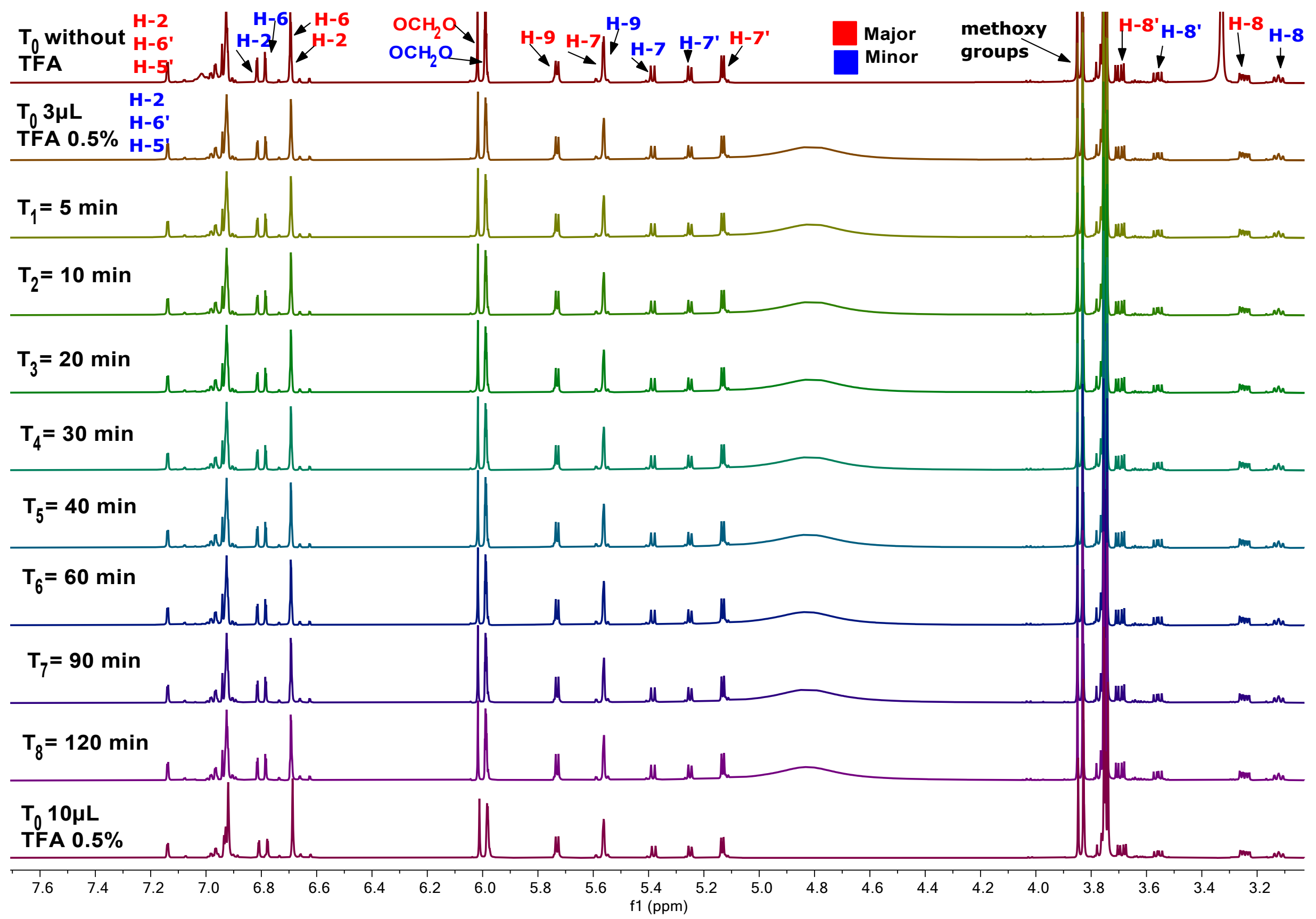

Figure S19. Effect of trifluoroacetic acid (TFA) at ${ }^{1} \mathrm{HNMR}$ spectrum of ciquitin A (1, DMSO, $\left.500 \mathrm{MHz}\right)$ 


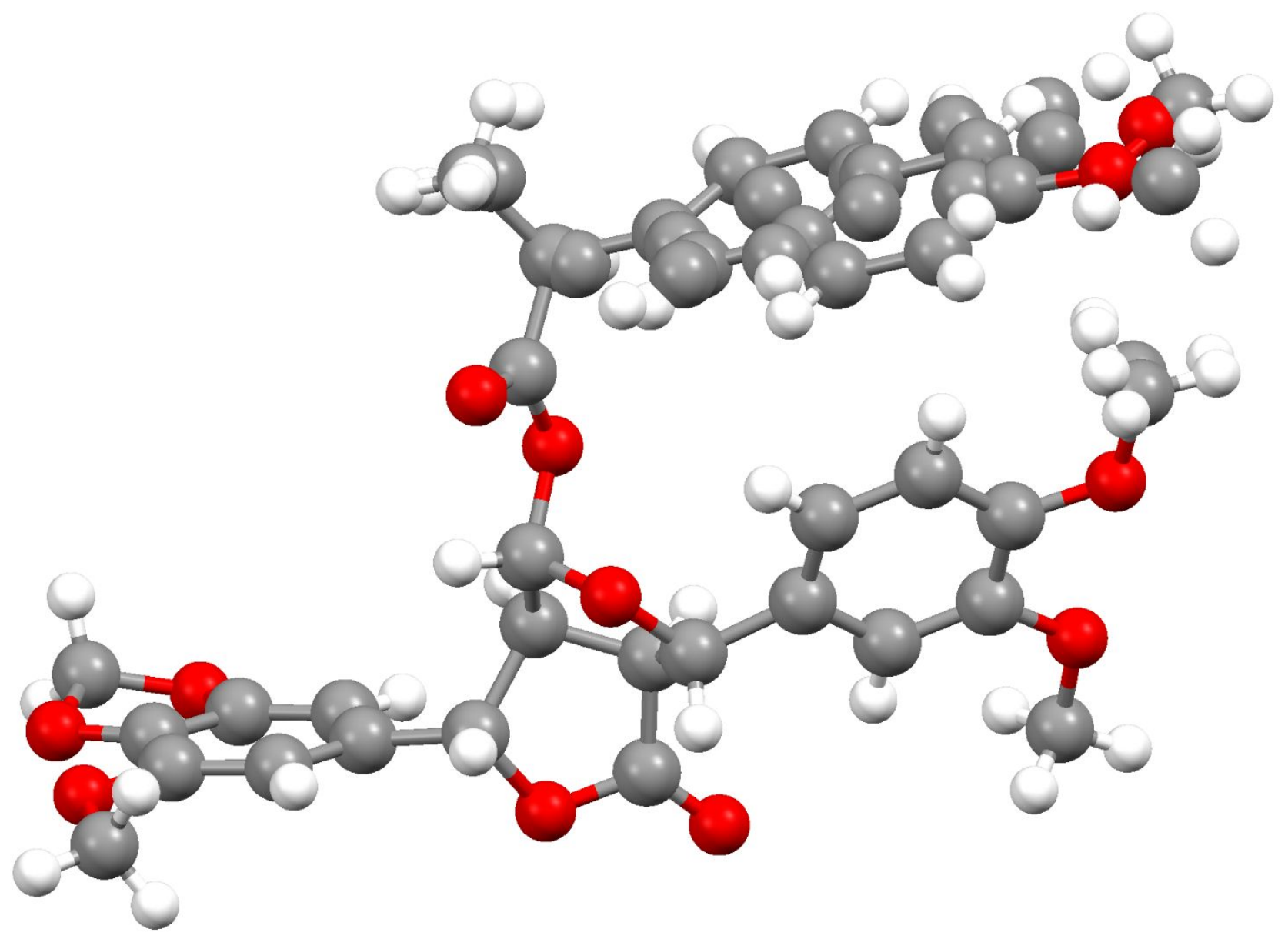

Figure S20. X-Ray ORTEP diagram of (9S)-naproxyl-ciquitin A (1A, CCDC 1937987) 
Table S2. Crystal data and structure refinement for cu 047RGMY190m.

Identification code

Empirical formula

Formula weight

Temperature

Wavelength

Crystal system

Space group

Unit cell dimensions

Volume

Z

Density (calculated)

Absorption coefficient

$\mathrm{F}(000)$

Crystal size

Theta range for data collection

Index ranges

Reflections collected

Independent reflections

Completeness to theta $=67.679^{\circ}$

Absorption correction

Refinement method

Data / restraints / parameters

Goodness-of-fit on $\mathrm{F}^{2}$

Final R indices [I $>2 \operatorname{sigma}(\mathrm{I})]$

$\mathrm{R}$ indices (all data)

Absolute structure parameter

Extinction coefficient

Largest diff. peak and hole
cu_047RGMY19_0m

C38.87 H37.28 O11

680.36

$100(2) \mathrm{K}$

$1.54178 \AA$

Monoclinic

$\mathrm{P} 21$

$\mathrm{a}=13.6524(5) \AA$

$\alpha=90^{\circ}$.

$\mathrm{b}=6.5443(3) \AA$

$\beta=104.473(3)^{\circ}$.

$\mathrm{c}=19.0669(8) \AA$

$\gamma=90^{\circ}$.

1649.48(12) $\AA^{3}$

2

$1.370 \mathrm{Mg} / \mathrm{m}^{3}$

$0.832 \mathrm{~mm}^{-1}$

717

$0.189 \times 0.033 \times 0.023 \mathrm{~mm}^{3}$

2.393 to $71.059^{\circ}$.

$-16<=\mathrm{h}<=16,-8<=\mathrm{k}<=7,-23<=\mathrm{l}<=23$

26939

$6035[\mathrm{R}(\mathrm{int})=0.0528]$

$100.0 \%$

None

Full-matrix least-squares on $\mathrm{F}^{2}$

6035 / 1176 / 689

1.030

$\mathrm{R} 1=0.0510, \mathrm{wR} 2=0.1251$

$\mathrm{R} 1=0.0629, \mathrm{wR} 2=0.1340$

$-0.19(15)$

$\mathrm{n} / \mathrm{a}$

0.540 and -0.342 e. $\AA^{-3}$ 


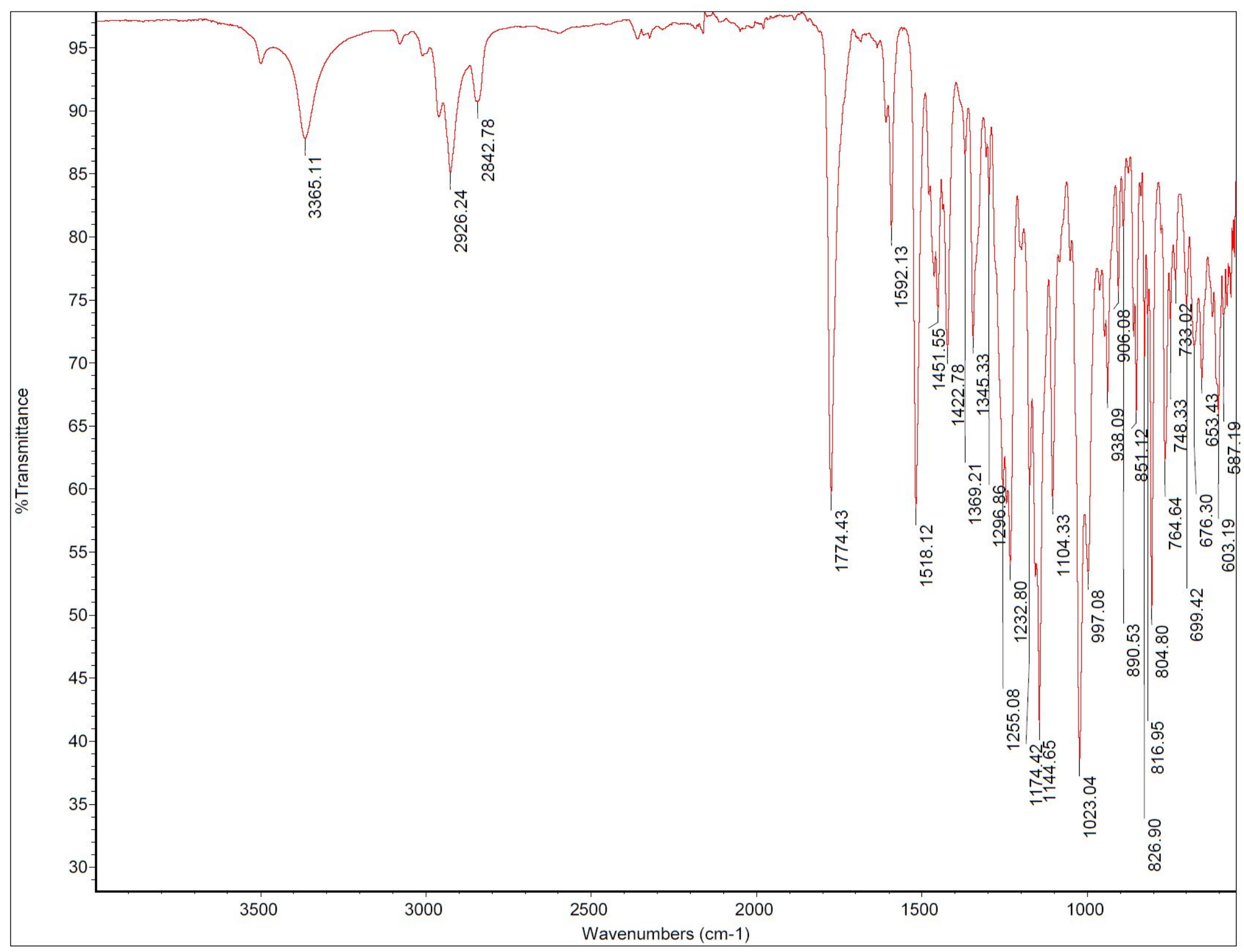

Figure S21. IR $\left(\mathrm{CDCl}_{3}\right)$ of ciquitin B (2) 


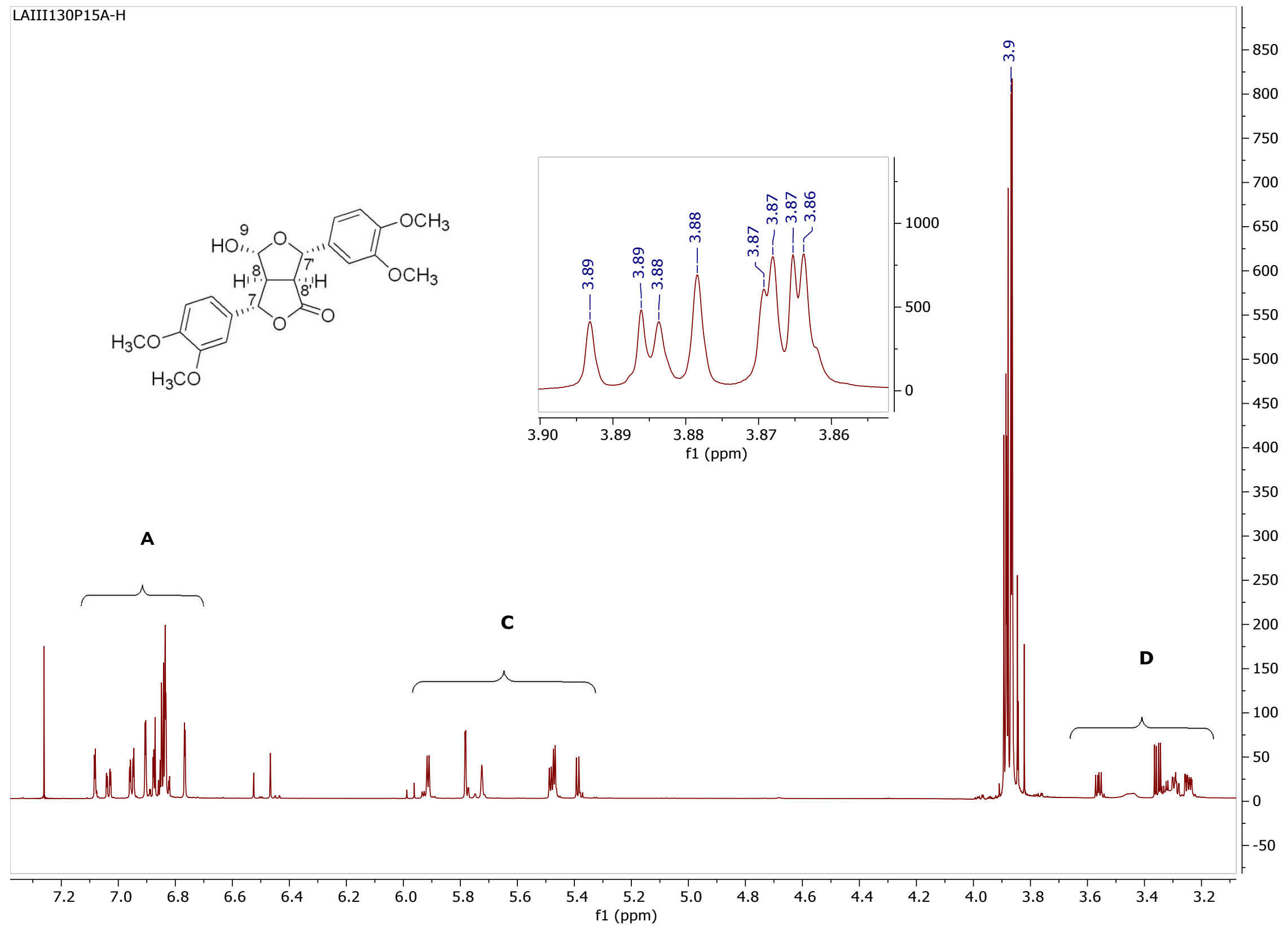

Figure S22. ${ }^{1} \mathrm{HNMR}\left(\mathrm{CDCl}_{3}, 400 \mathrm{MHz}\right)$ of ciquitin B (2) 

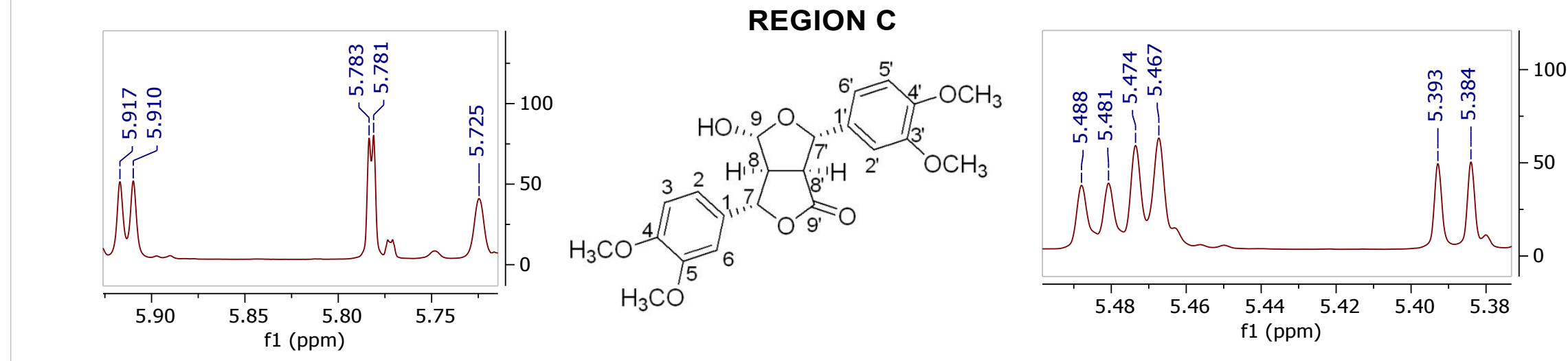

REGION D

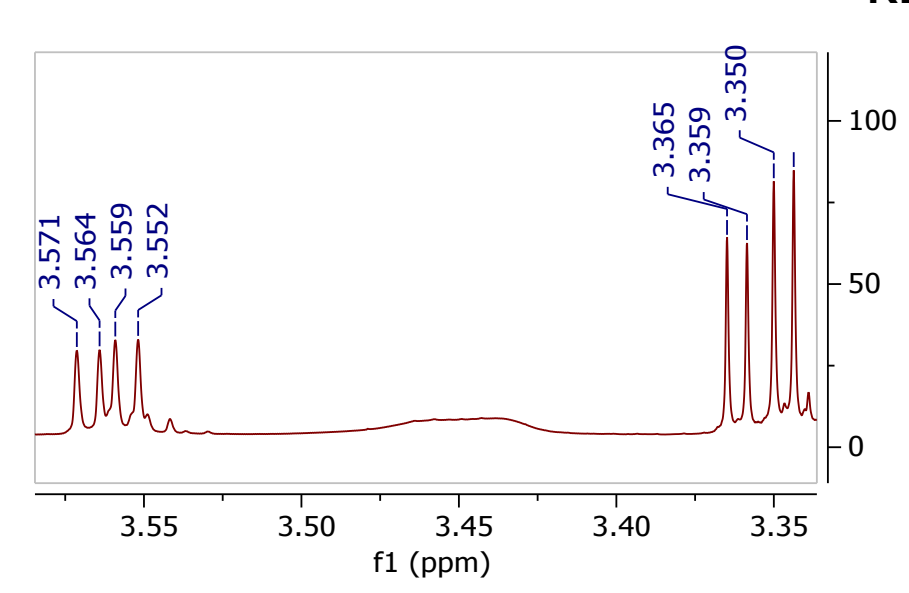

REGION A

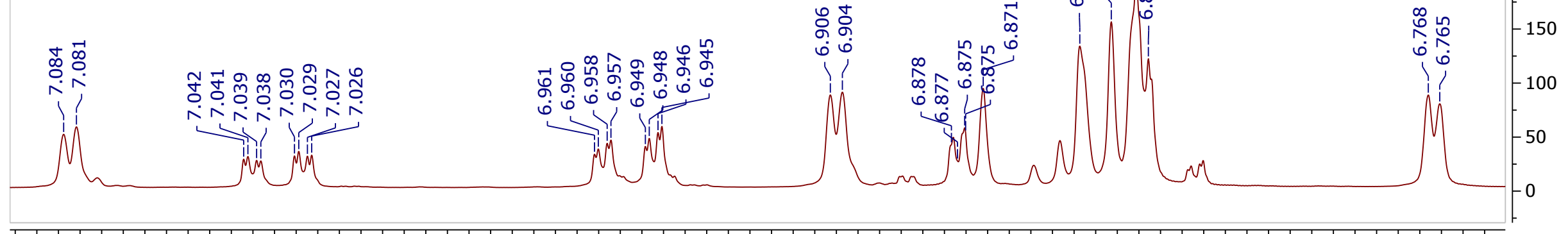

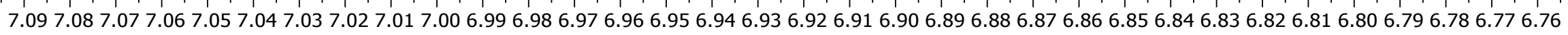
f1 (ppm)

Figure S23. ${ }^{1} \mathrm{HNMR}\left(\mathrm{CDCl}_{3}, 400 \mathrm{MHz}\right)$ ampliation of ciquitin $\mathrm{B}(2)$ 
13C NMR (100 MHz, CDC1) $\delta 177.28,176.29,149.81,149.74,149.56,149.39,149.36$, $149.31,149.05,149.03,134.03,133.15,132.43,130.74,118.44,118.37,117.93,117.56$, $111.51,111.37,111.37,111.17,109.35,108.78,108.69,108.61,102.91,98.47,85.08,82.89$, $81.09,79.91,58.43,56.27,56.25,56.22,56.22,56.19,56.17,56.17,56.14,53.78,52.84,51.85$
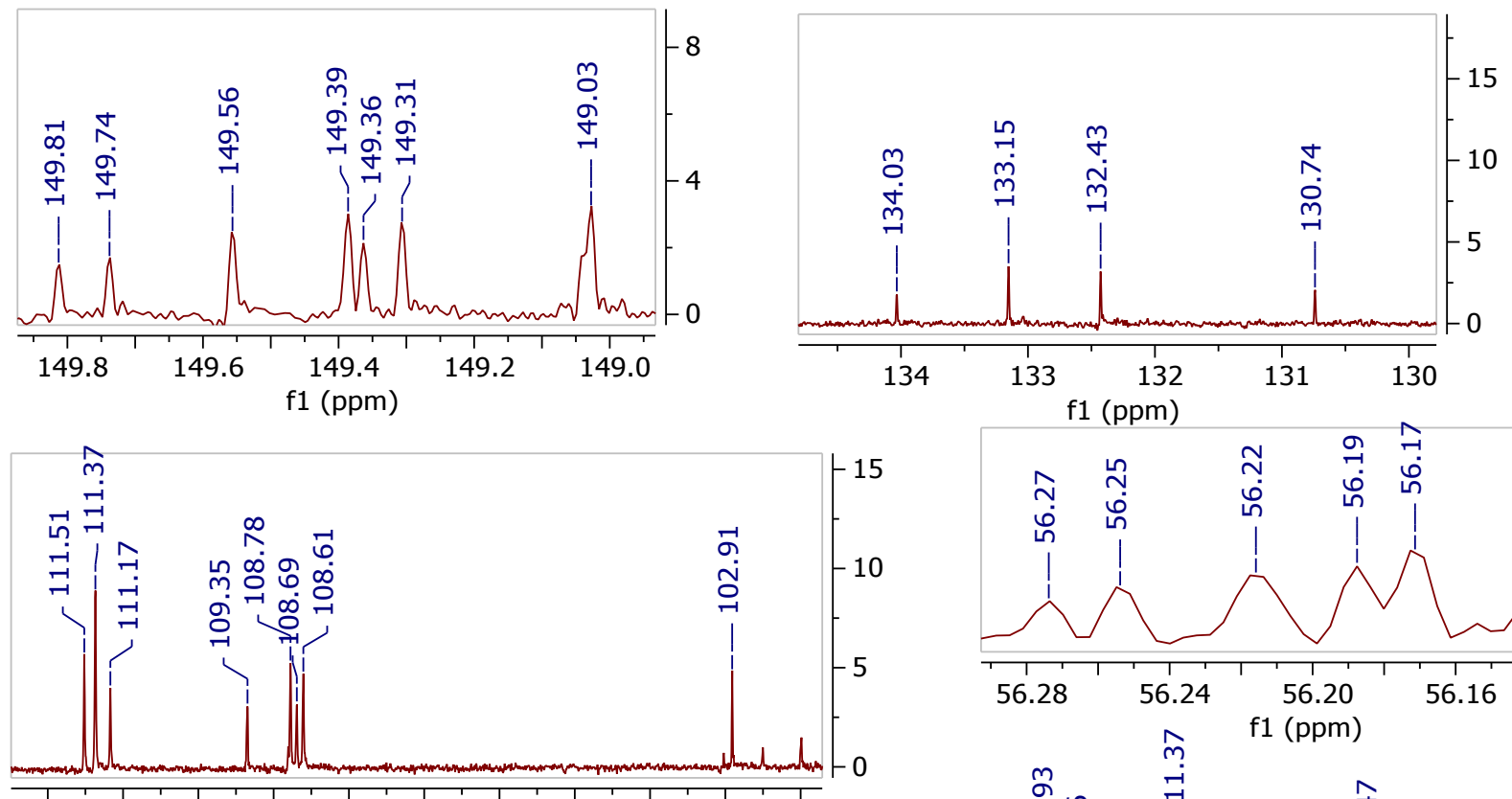

$\begin{array}{lllllllllll}112 & 111 & 110 & 109 & 108 & 107 & 106 & 105 & 104 & 103 & 102\end{array}$ f1 (ppm)
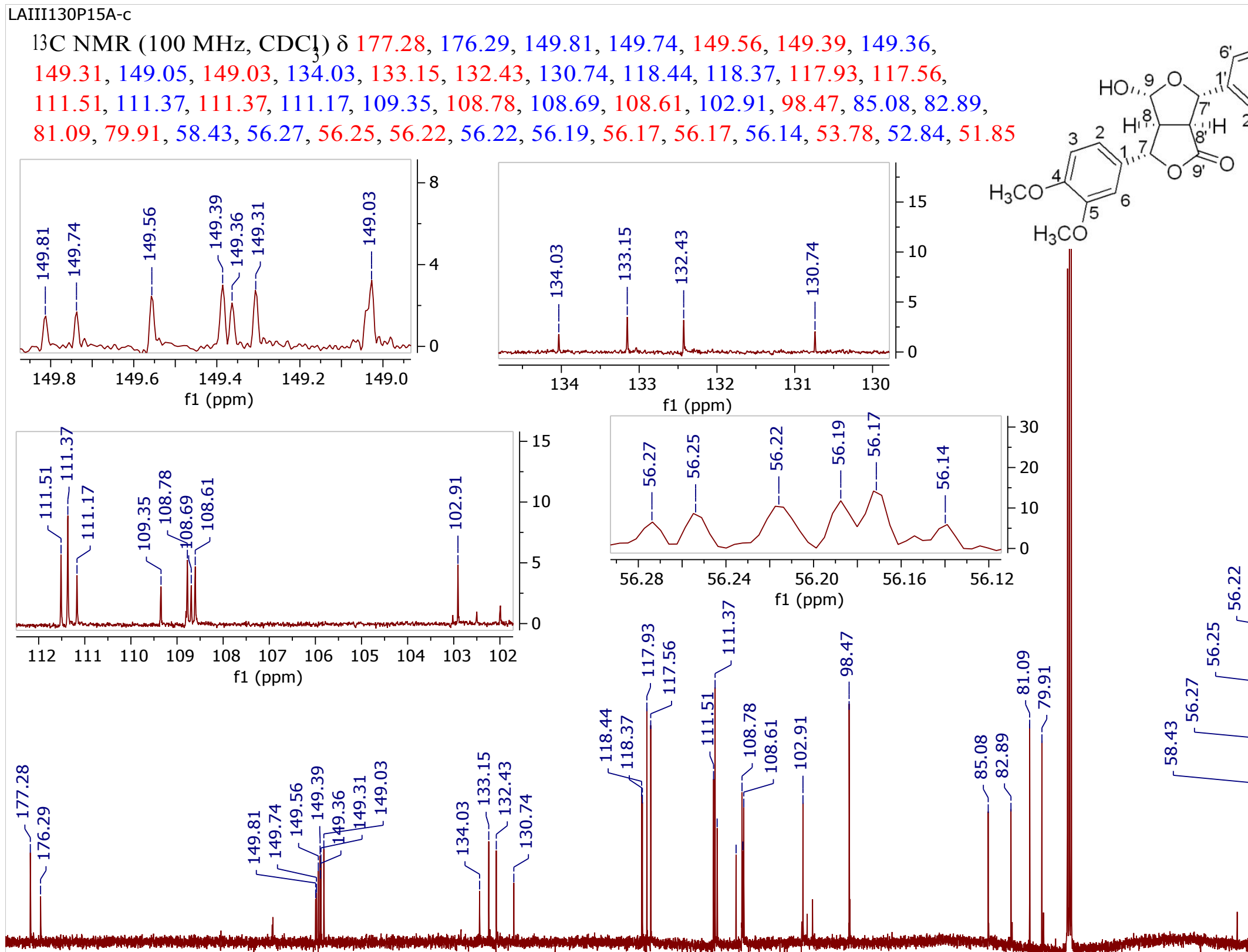

$-32$
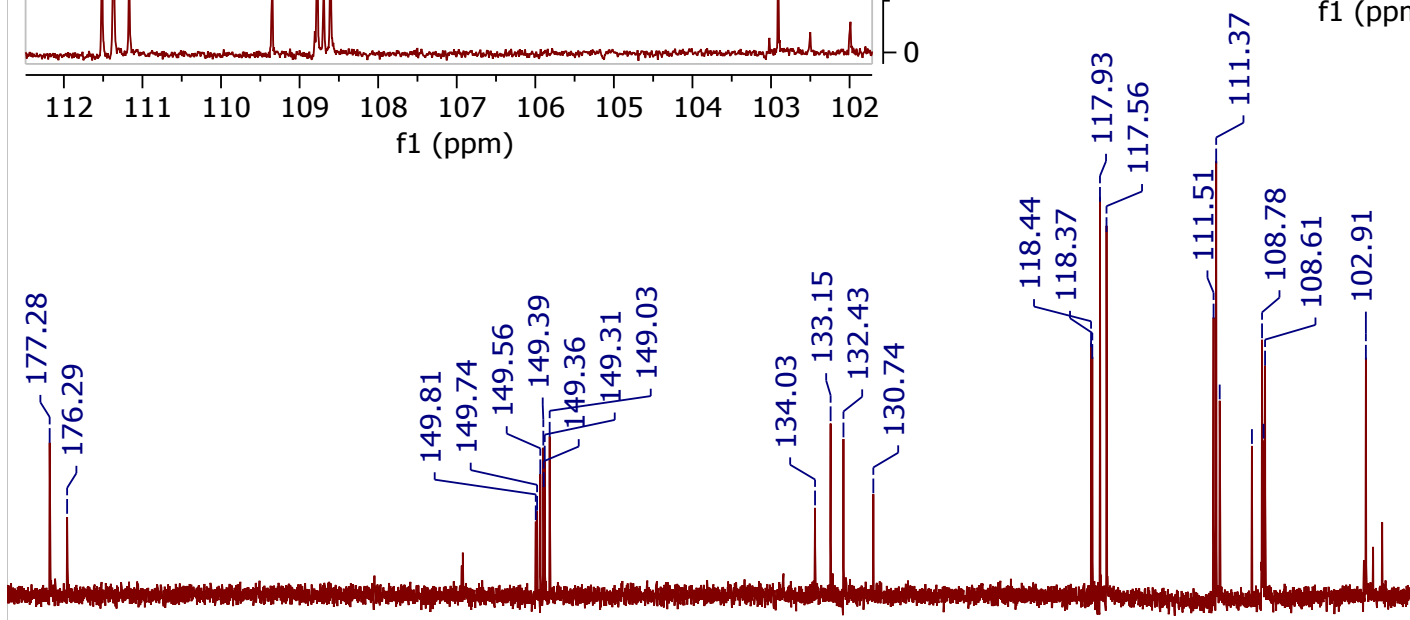

๙े

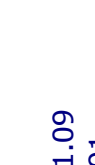

वे नु

175

$\begin{array}{lllllll}170 & 165 & 160 & 155 & 150 & 145 & 140\end{array}$

$135 \quad 130 \quad 125$ $\begin{array}{llll}120 & 115 & 110 & 105 \\ \mathrm{f} 1(\mathrm{ppm}) & \end{array}$

Figure S24. ${ }^{13} \mathrm{CNMR}\left(\mathrm{CDCl}_{3}, 100 \mathrm{MHz}\right)$ of ciquitin $\mathrm{B}(\mathbf{2})$ 


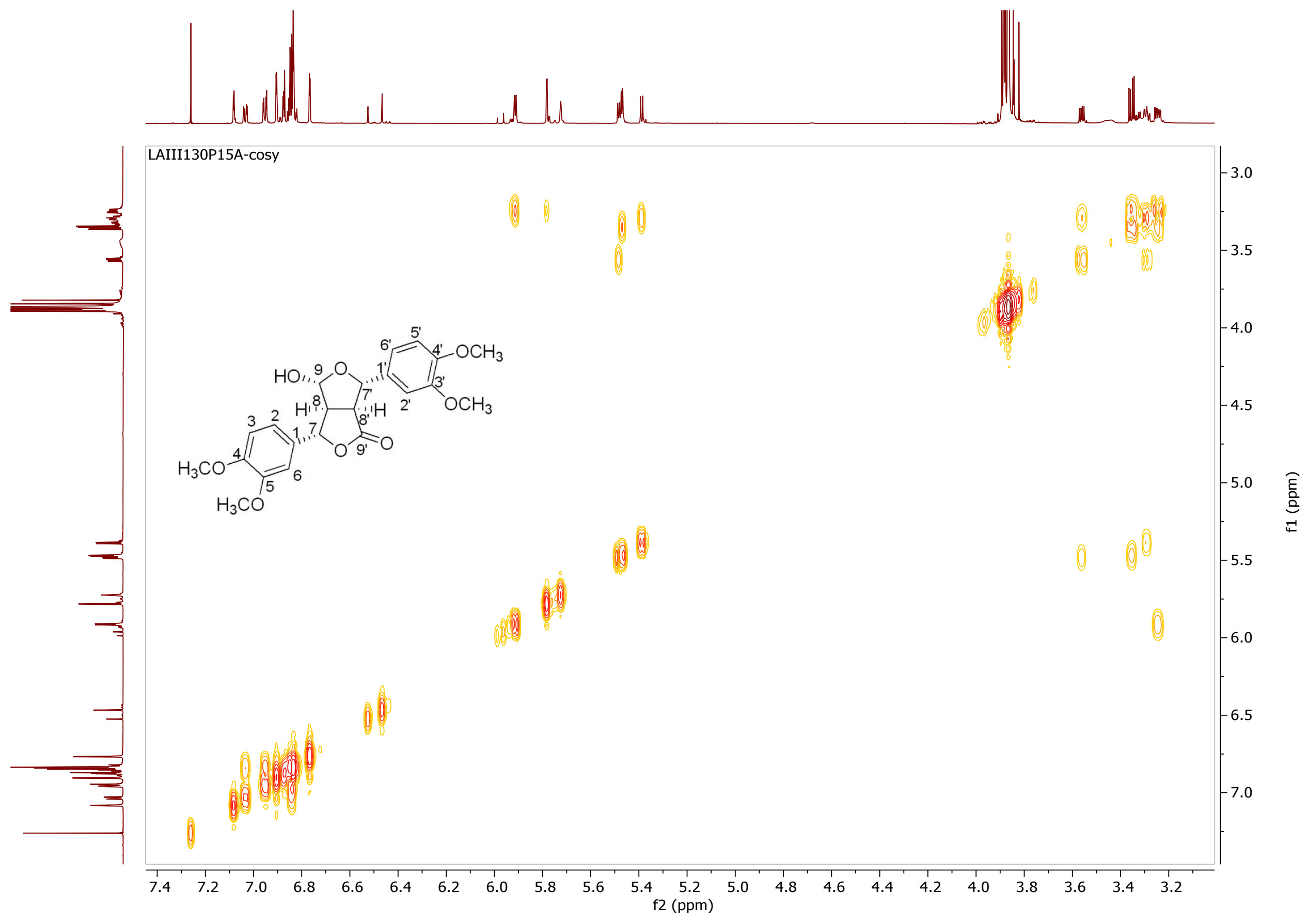

Figure S25. COSY $\left(\mathrm{CDCl}_{3}, 400 \mathrm{MHz}\right)$ of ciquitin B (2) 


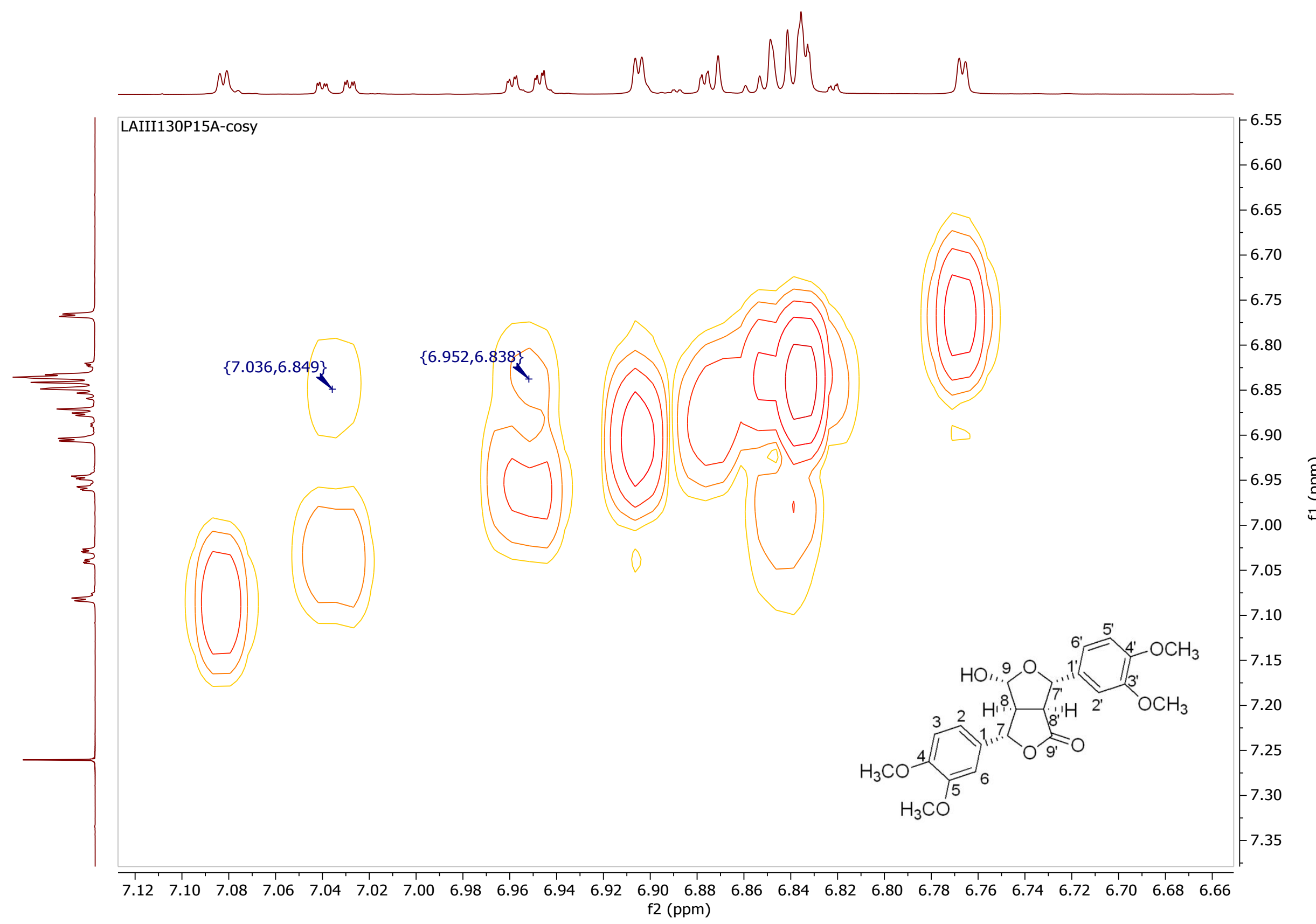

Figure S26. Expansion COSY $\left(\mathrm{CDCl}_{3}, 400 \mathrm{MHz}\right)$ of ciquitin B (2) 


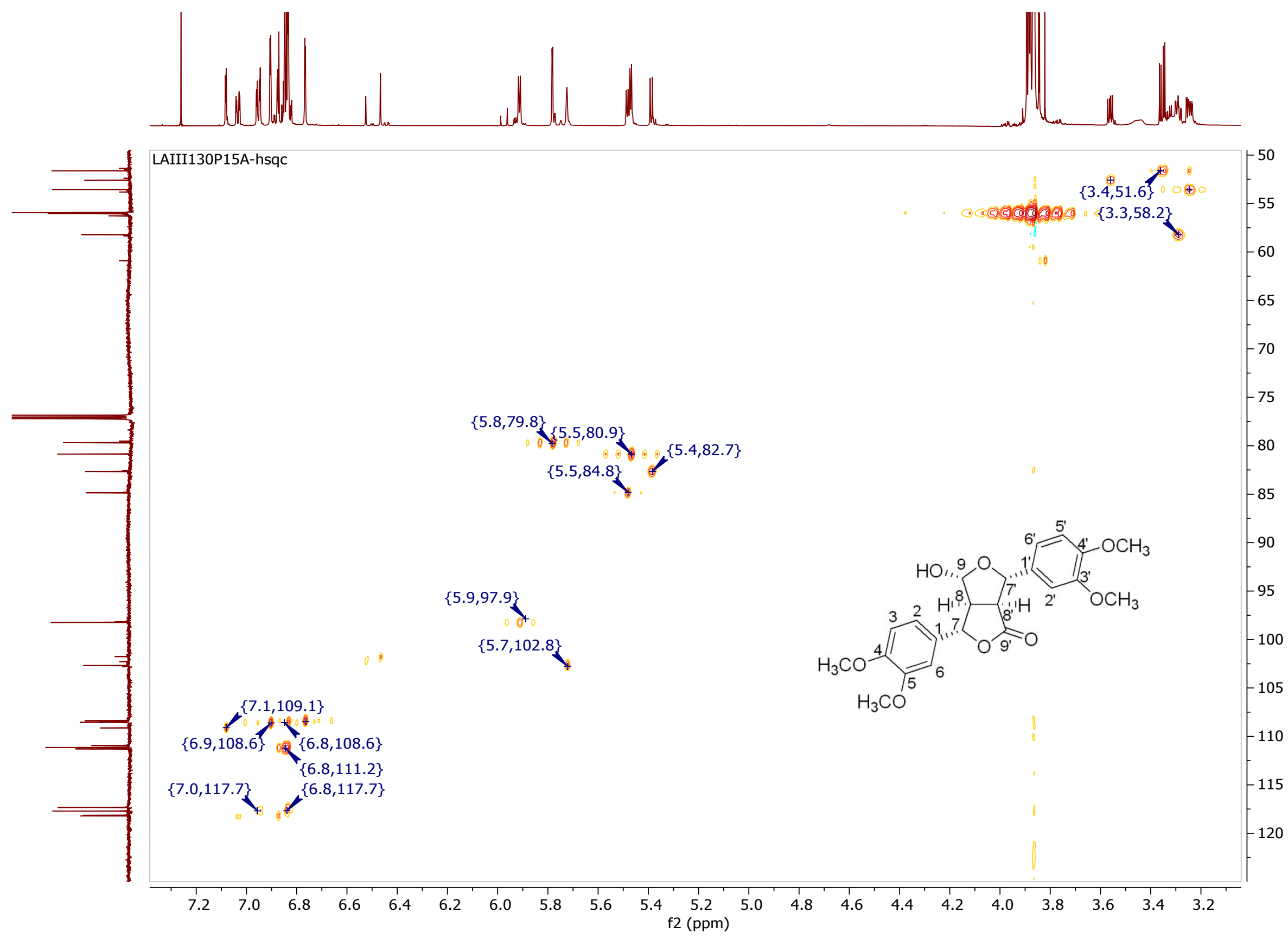

Figure S27. $\mathrm{HSQC}\left(\mathrm{CDCl}_{3}, 400 \mathrm{MHz}\right)$ of ciquitin B (2) 


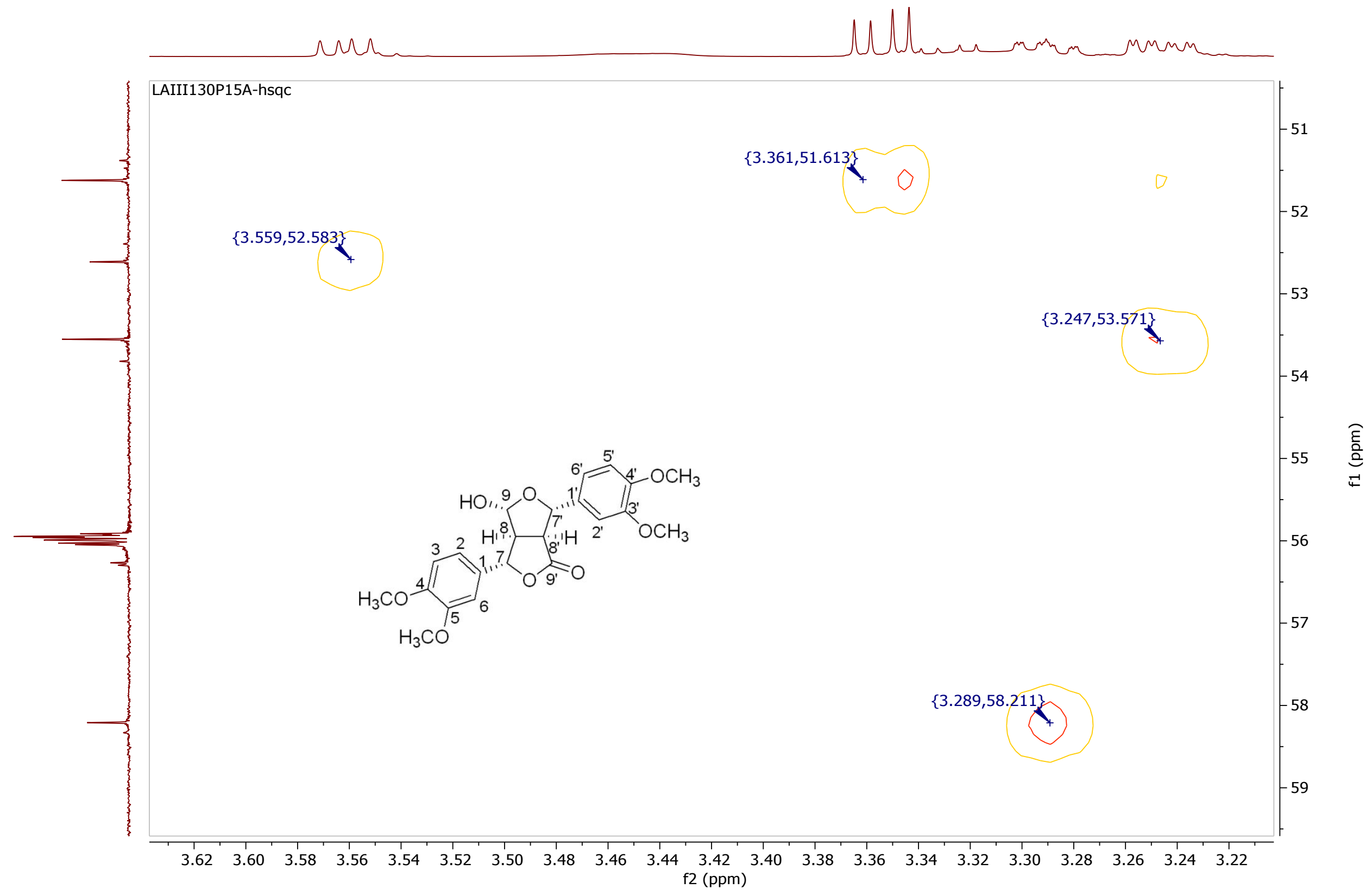

Figure S28. HSQC $\left(\mathrm{CDCl}_{3}, 400 \mathrm{MHz}\right)$ of ciquitin B (2) 


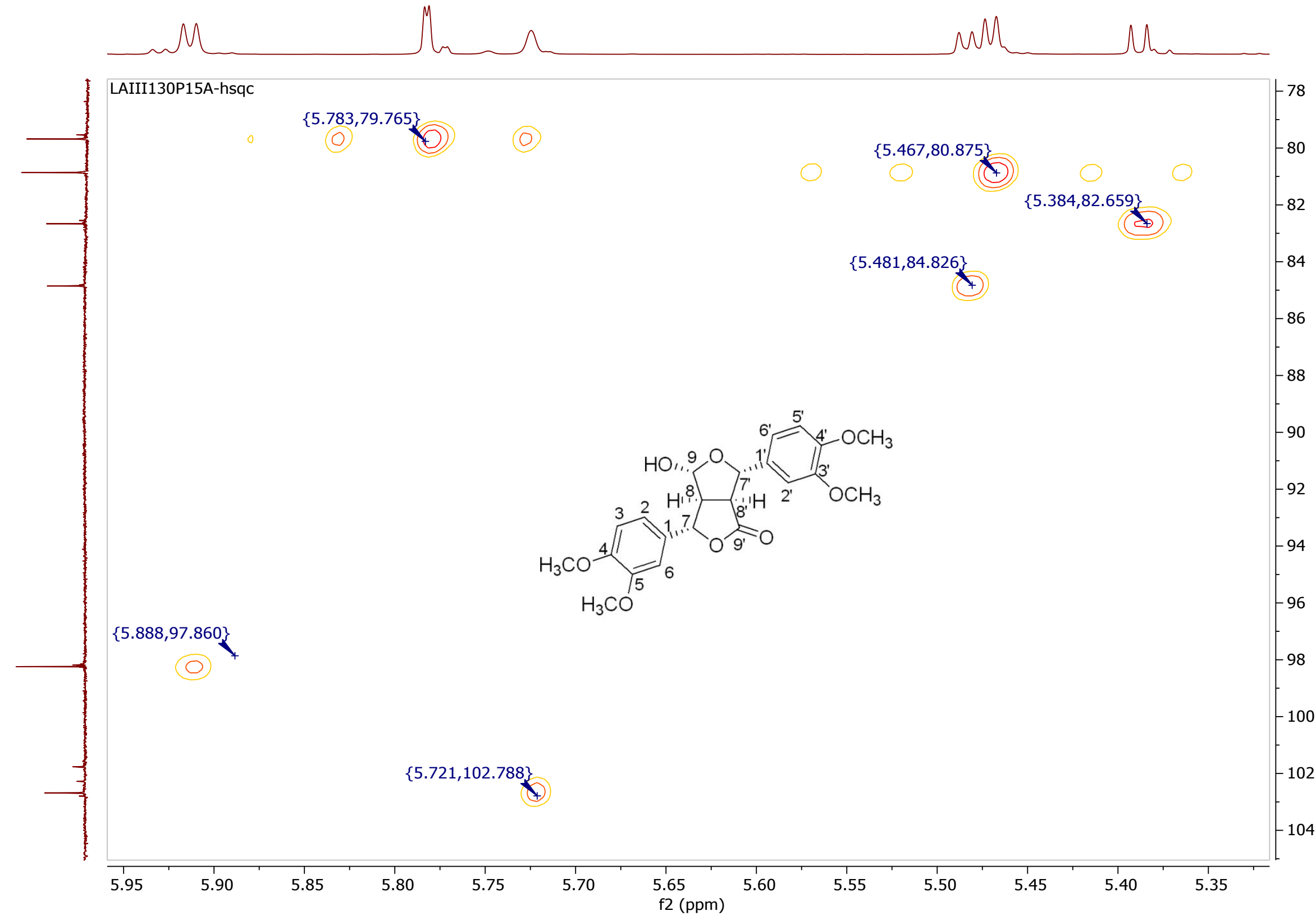

Figure S29. HSQC $\left(\mathrm{CDCl}_{3}, 400 \mathrm{MHz}\right)$ of ciquitin B (2) 


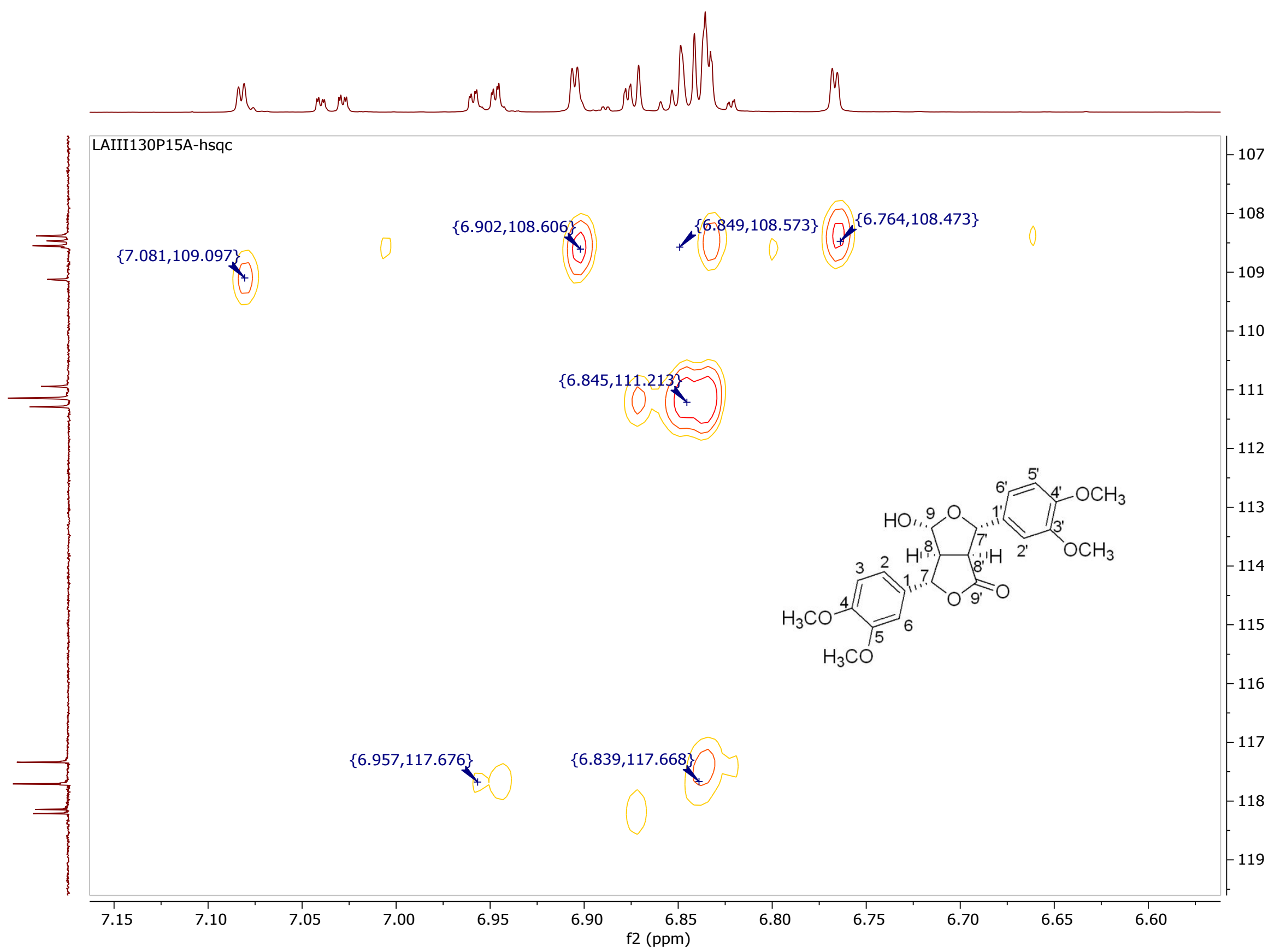

Figure S30. HSQC $\left(\mathrm{CDCl}_{3}, 400 \mathrm{MHz}\right)$ of ciquitin B (2) 


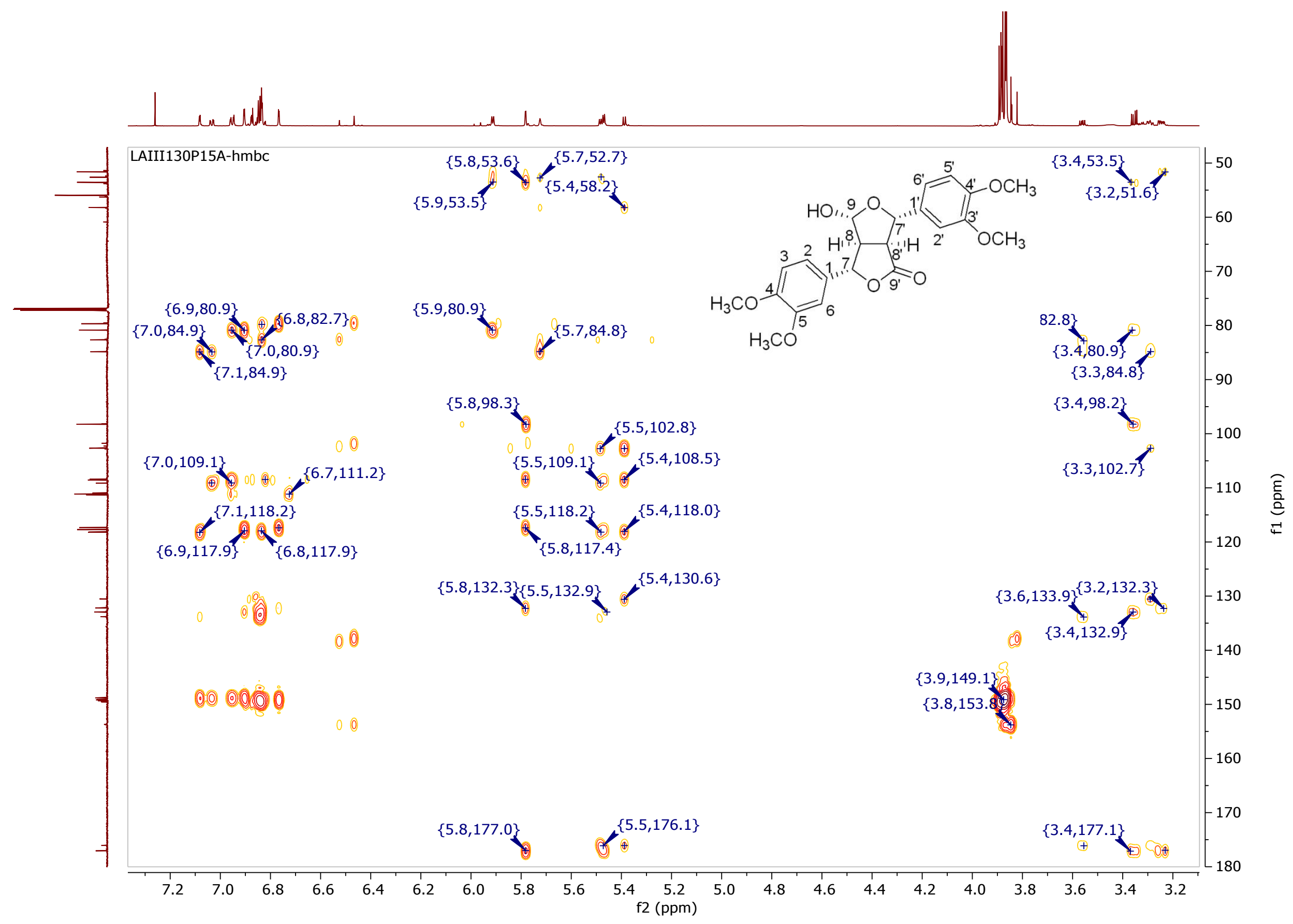

Figure S31. $\mathrm{HMBC}\left(\mathrm{CDCl}_{3}, 400 \mathrm{MHz}\right)$ of ciquitin B (2) 


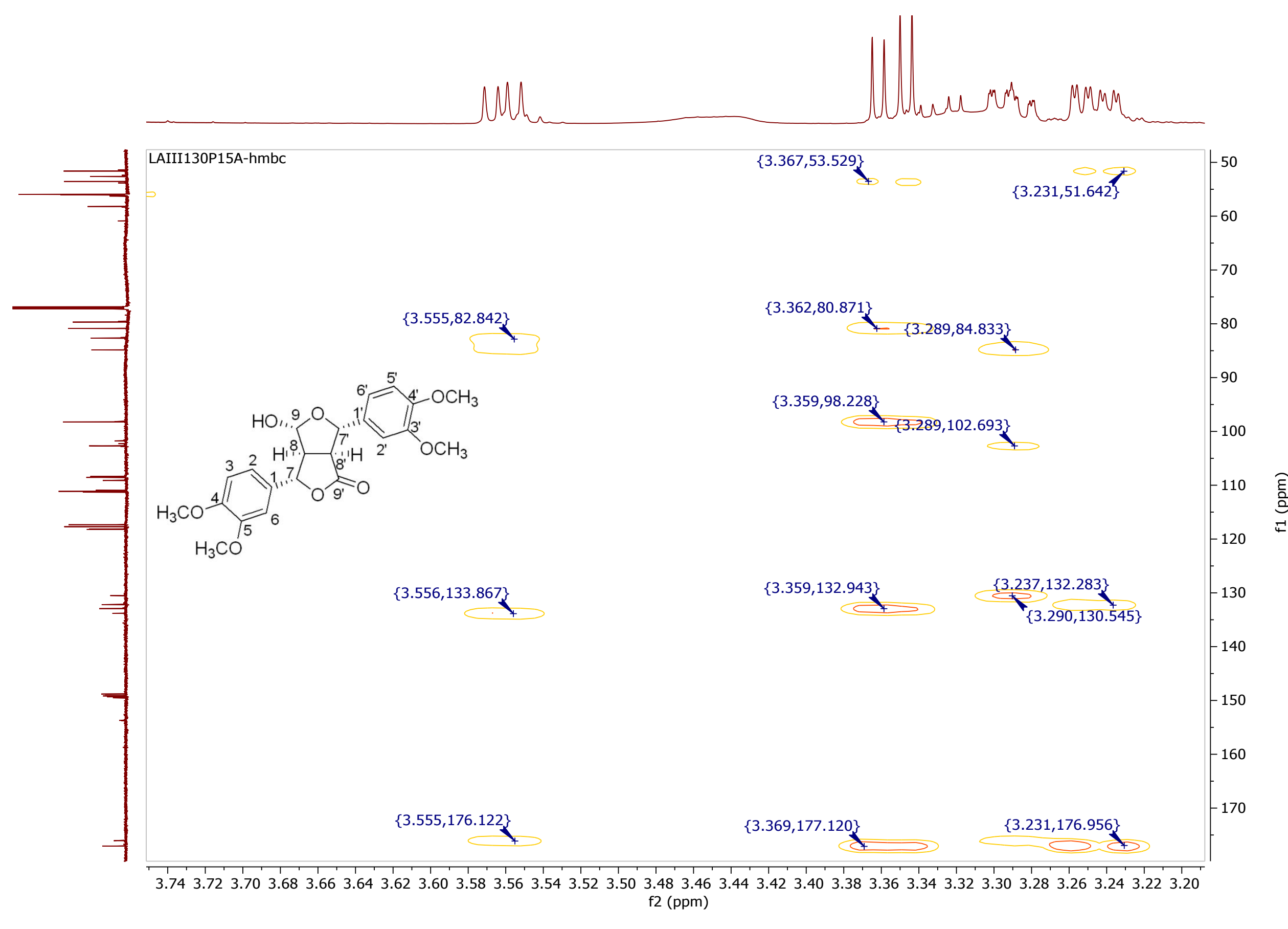

Figure S32. $\mathrm{HMBC}\left(\mathrm{CDCl}_{3}, 400 \mathrm{MHz}\right)$ of ciquitin B (2) 


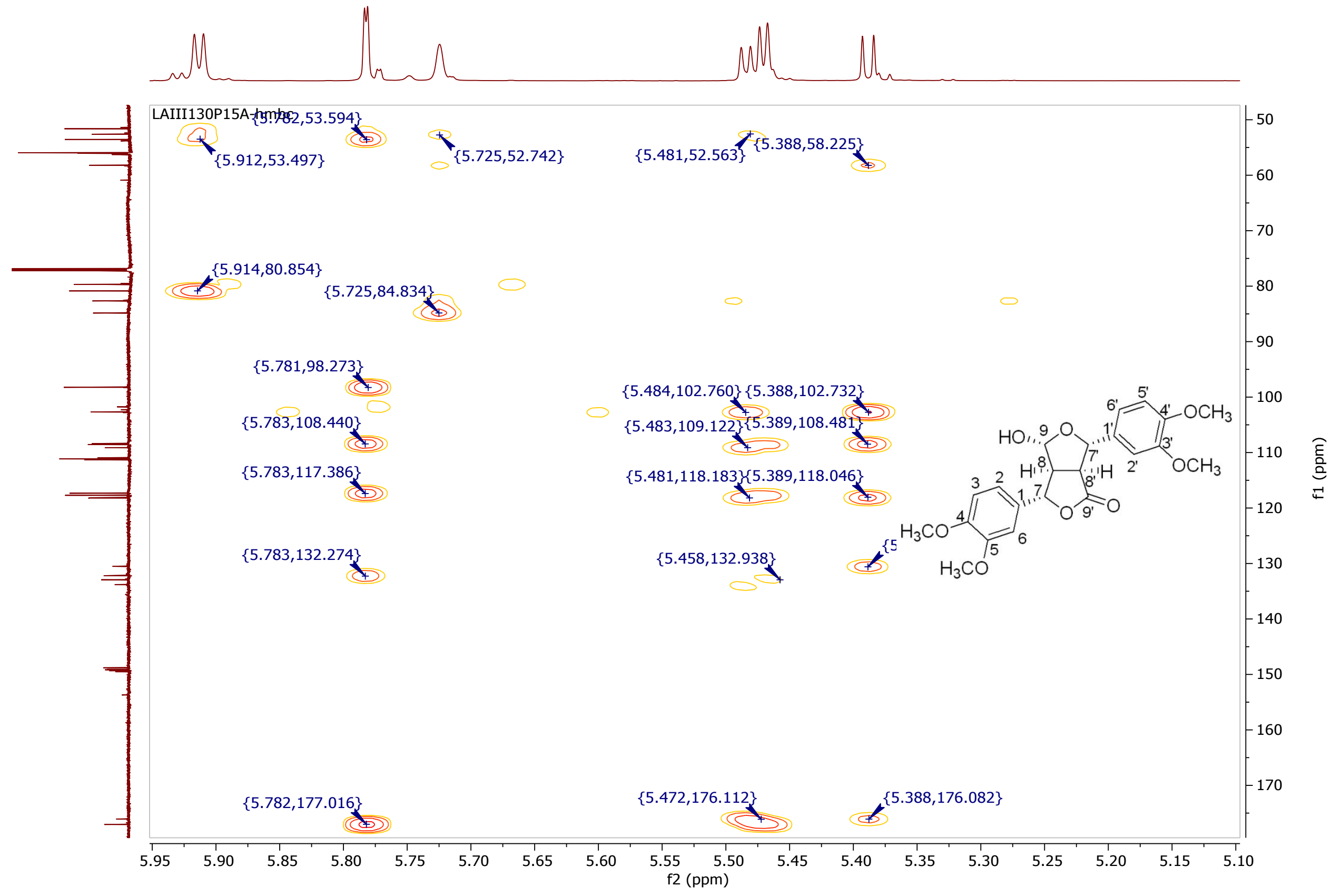

Figure S33. $\mathrm{HMBC}\left(\mathrm{CDCl}_{3}, 400 \mathrm{MHz}\right)$ of ciquitin B (2) 


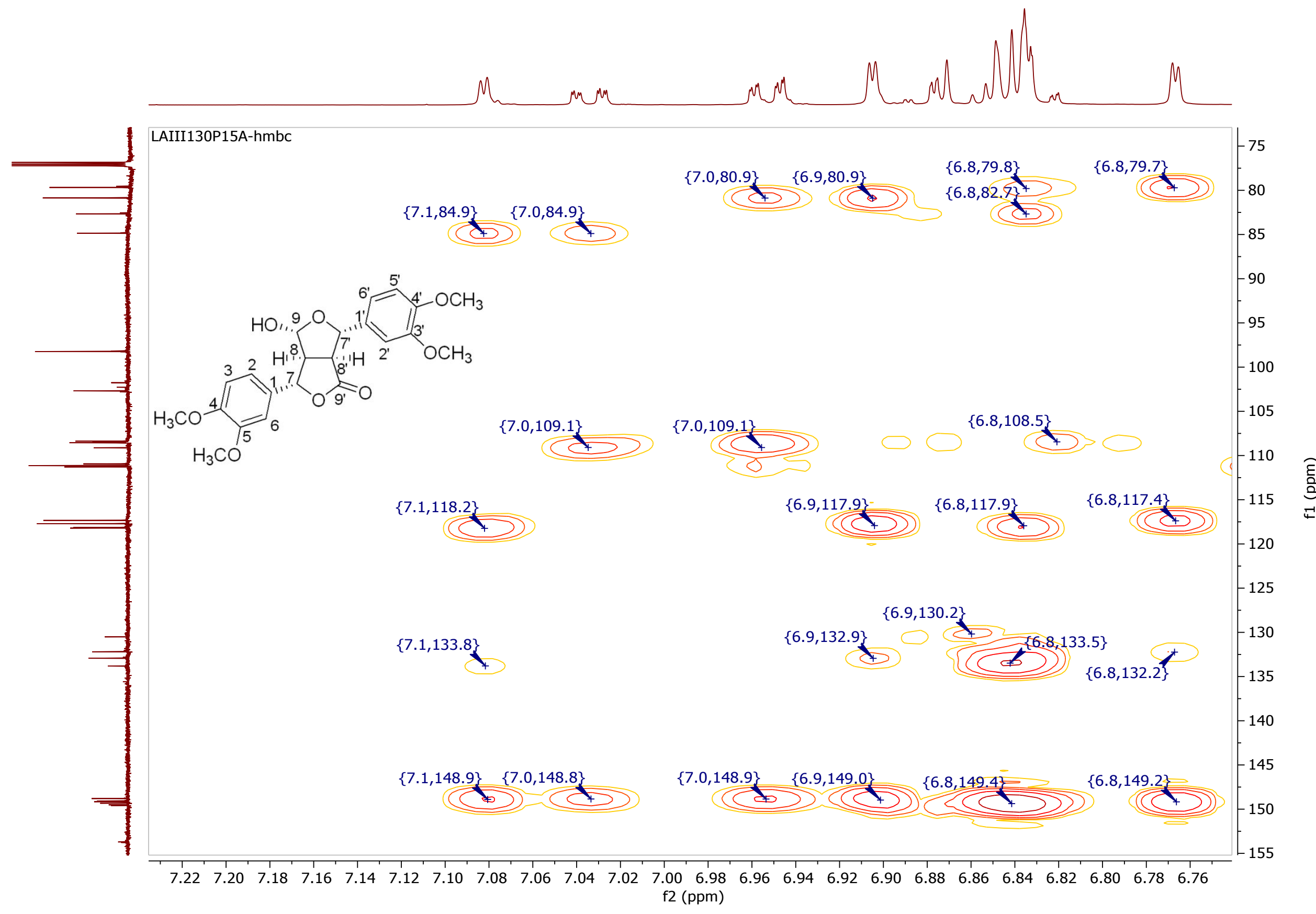

Figure S34. $\mathrm{HMBC}\left(\mathrm{CDCl}_{3}, 400 \mathrm{MHz}\right)$ of ciquitin $\mathrm{B}$ (2) 


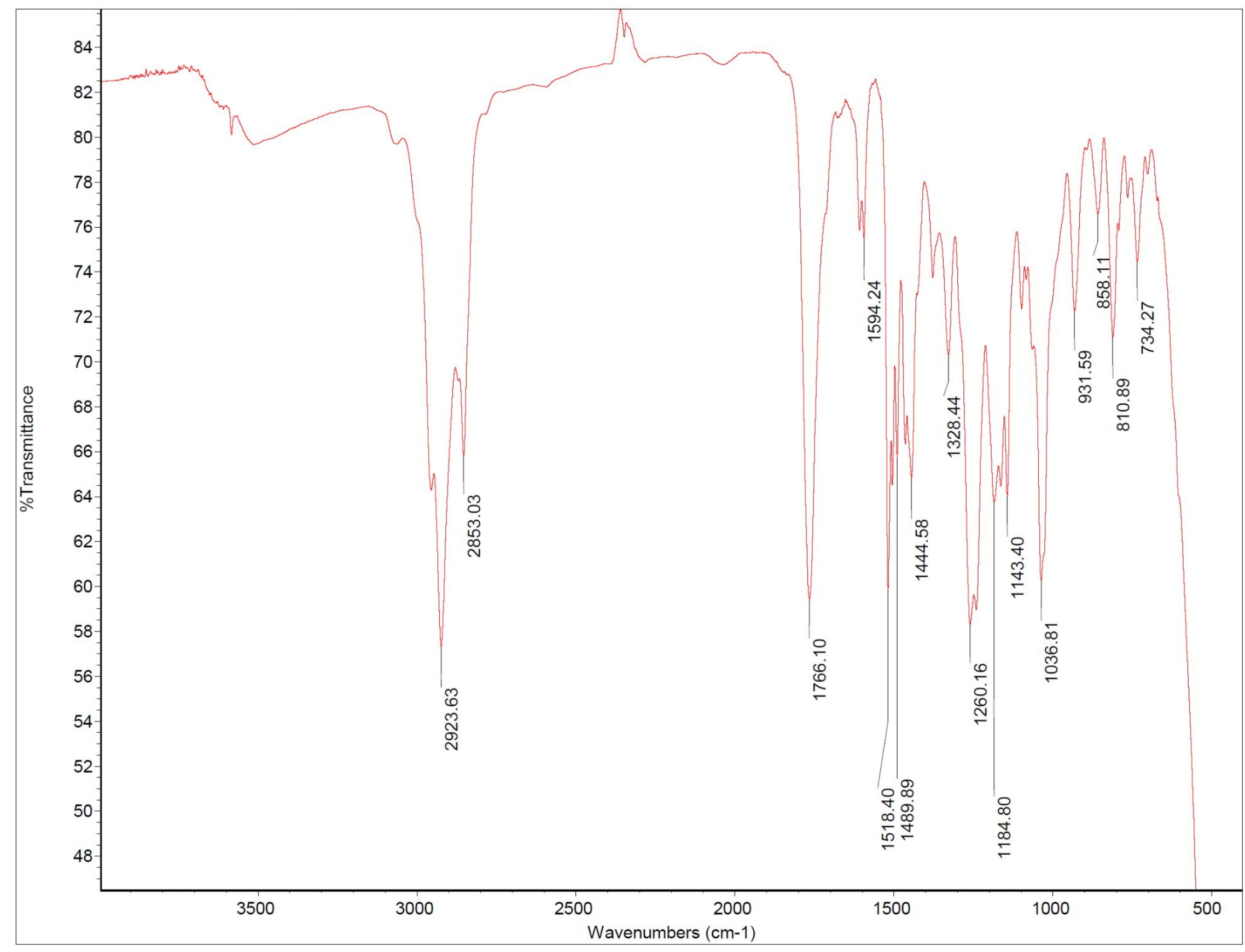

Figure S35. IR $\left(\mathrm{CDCl}_{3}\right)$ of ciquitin $\mathrm{C}(\mathbf{3})$ 


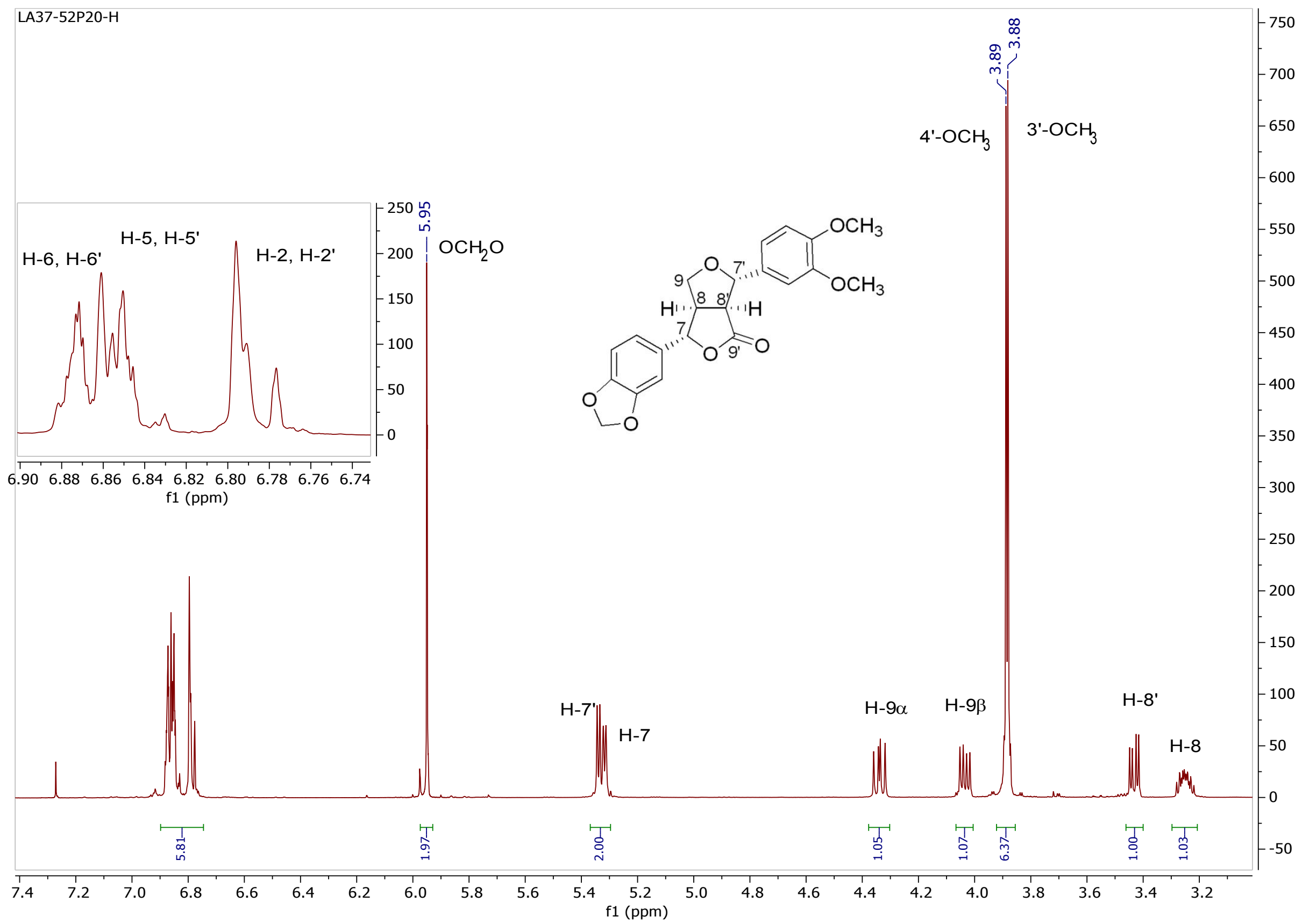

Figure S36. ${ }^{1} \mathrm{HNMR}\left(\mathrm{CDCl}_{3}, 400 \mathrm{MHz}\right)$ of ciquitin $\mathrm{C}(3)$ 

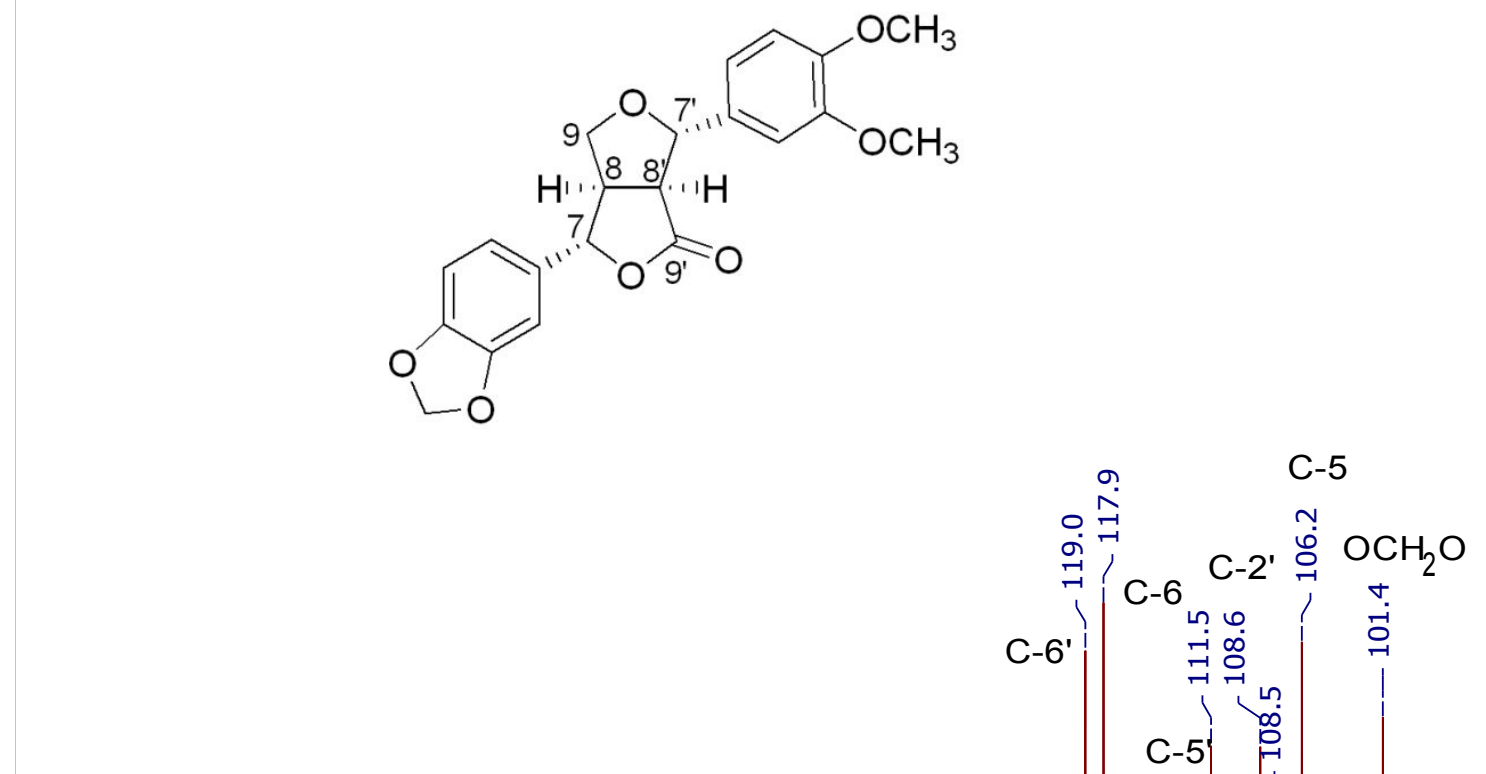

C-9'

웅

-

C-3' C-4'

C-1 C-1'

مิ

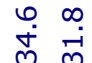

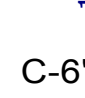

C-6')

C-6 일

寉 C-5

C-3 [

崩

| $-4$

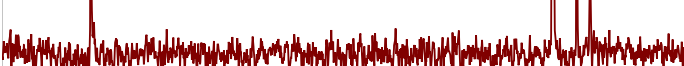

$\begin{array}{llll}180 & 175 & 170 & 1\end{array}$ 160155 $150 \quad 145 \quad 140$ $115 \quad 110$ $\begin{array}{lll}105 & 100 & 95\end{array}$

Figure S37. ${ }^{13} \mathrm{CNMR}\left(\mathrm{CDCl}_{3}, 400 \mathrm{MHz}\right)$ of ciquitin $\mathrm{C}(\mathbf{3})$ 


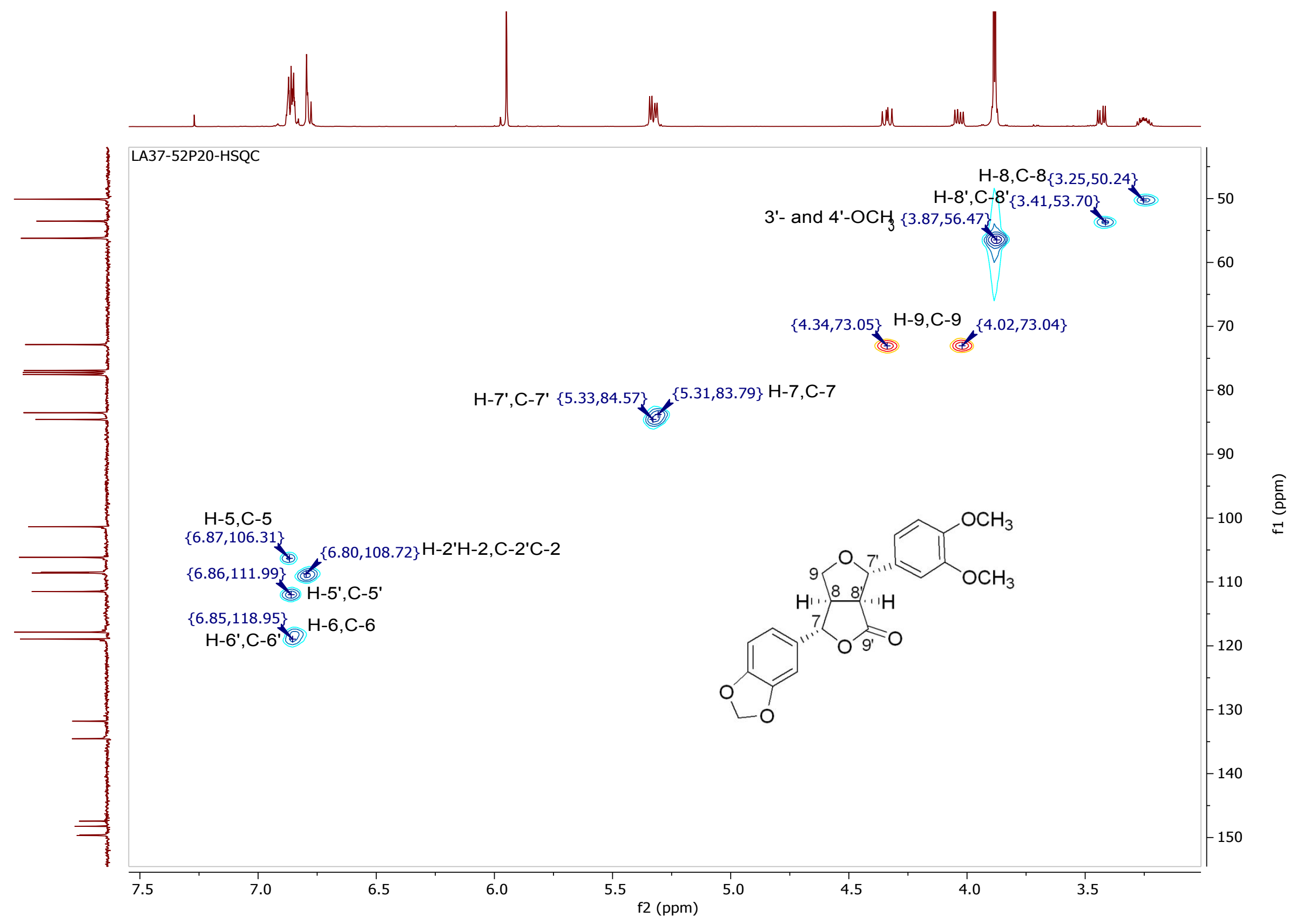

Figure S38. HSQC ( $\left.\mathrm{CDCl}_{3}, 400 \mathrm{MHz}\right)$ of ciquitin C (3) 


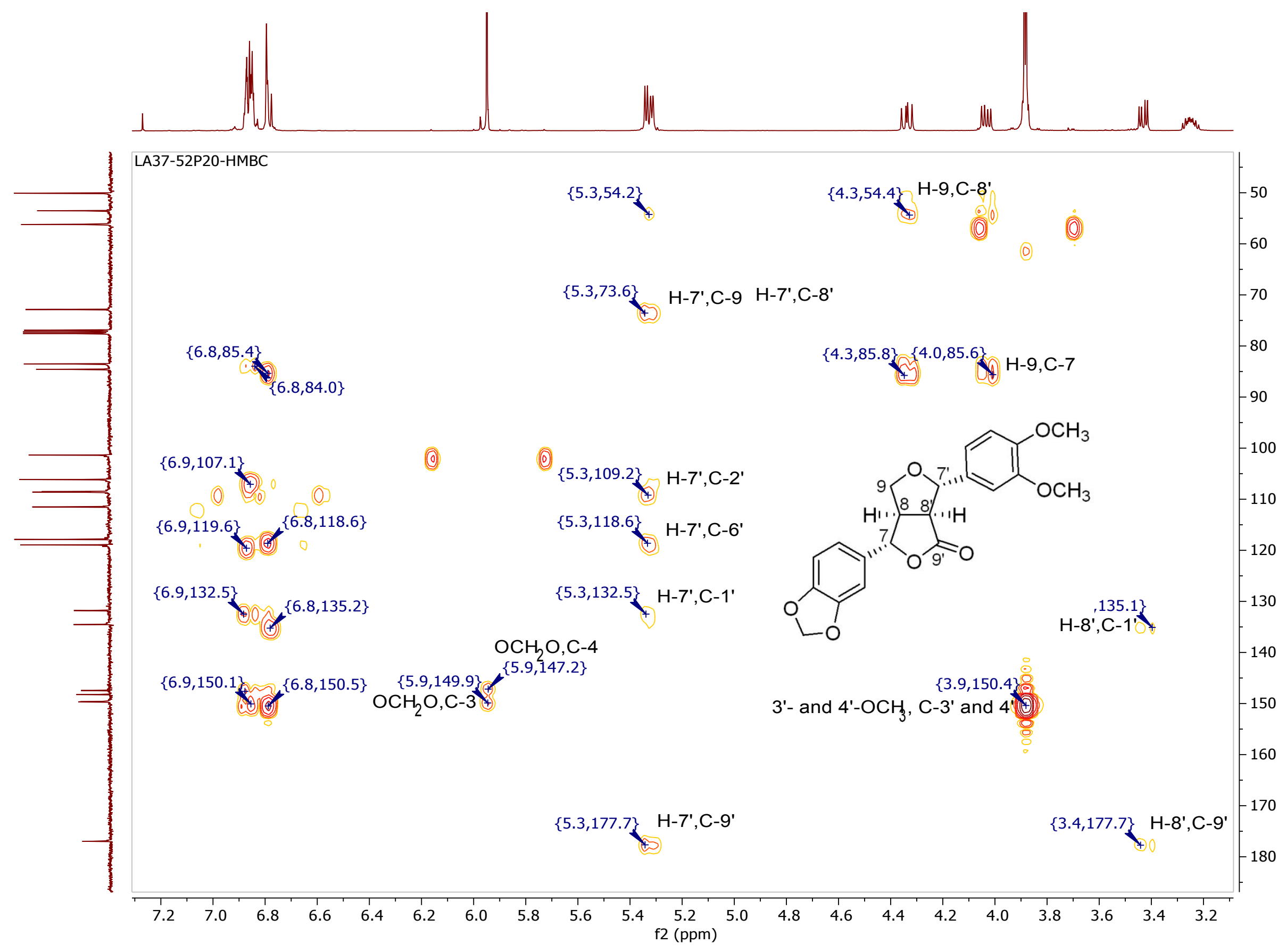

Figure S39. $\mathrm{HMBC}\left(\mathrm{CDCl}_{3}, 400 \mathrm{MHz}\right)$ of ciquitin $\mathrm{C} \mathrm{(3)}$ 


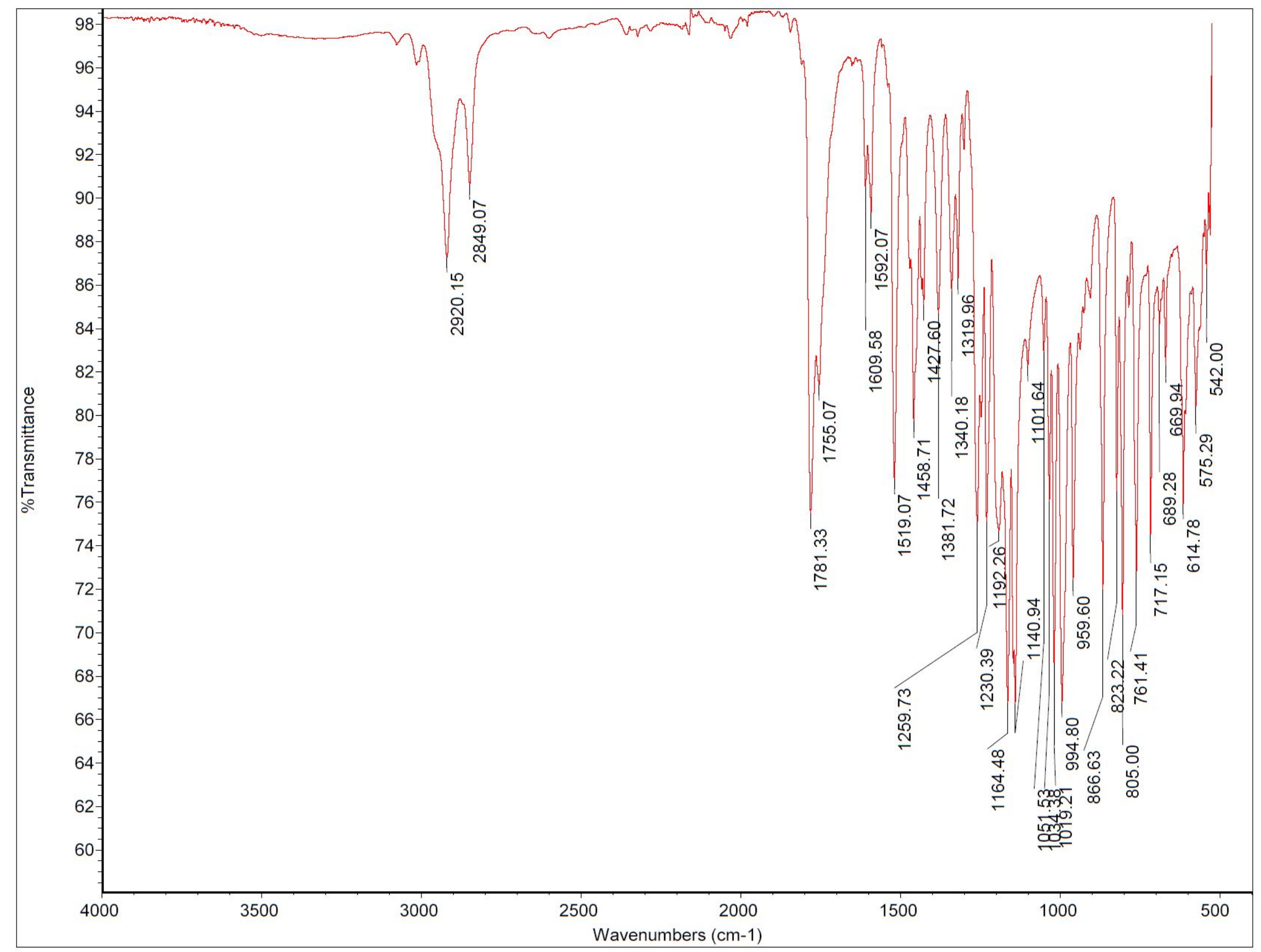

Figure S40. IR $\left(\mathrm{CDCl}_{3}\right)$ of (3S)-hydroxy-3',4'-dimethoxy-L-phenylalanine (5) 


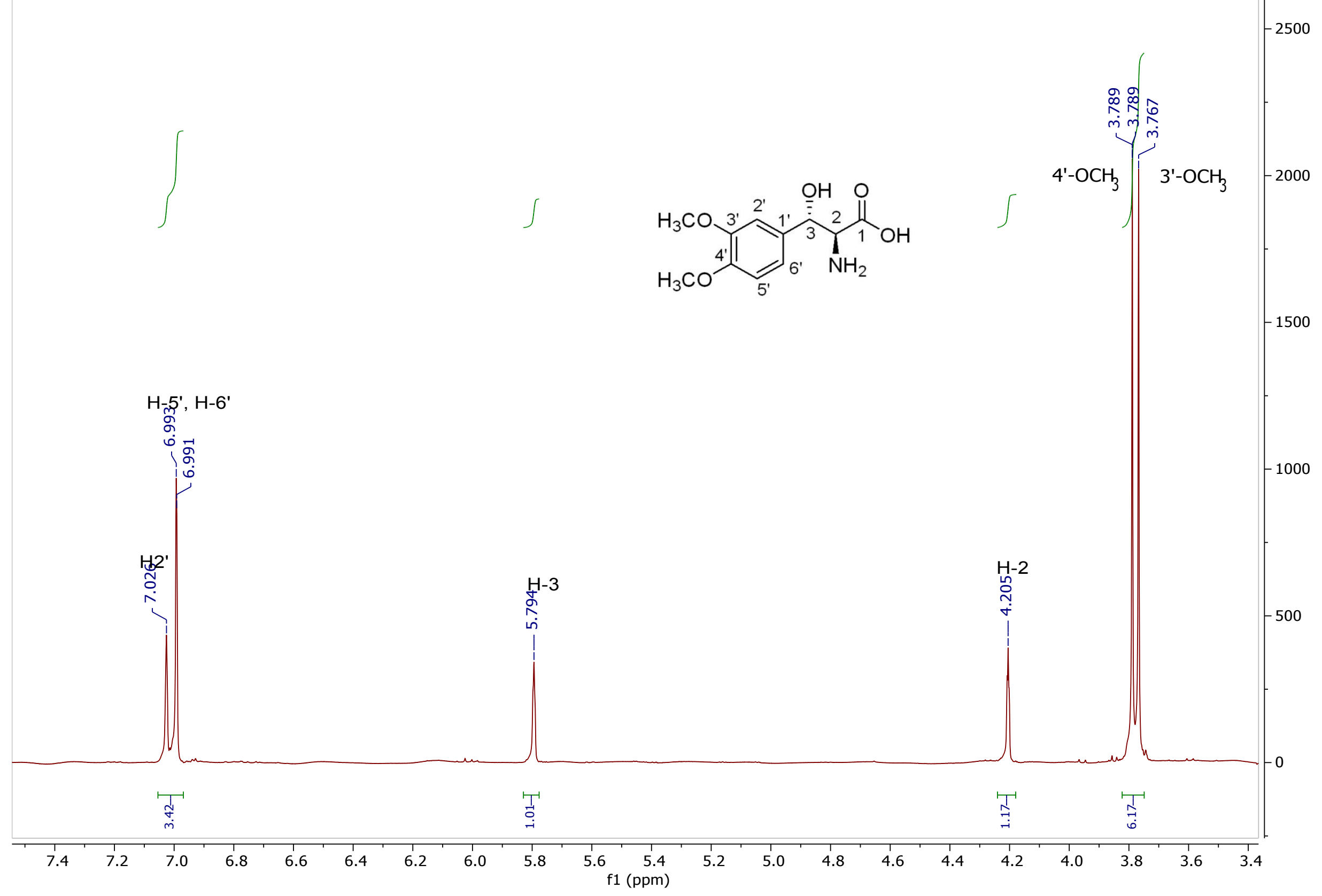

Figure S41. 'HNMR (DMSO, $400 \mathrm{MHz}$ ) of (3S)-hydroxy-3',4'-dimethoxy-L-phenylalanine (5) 

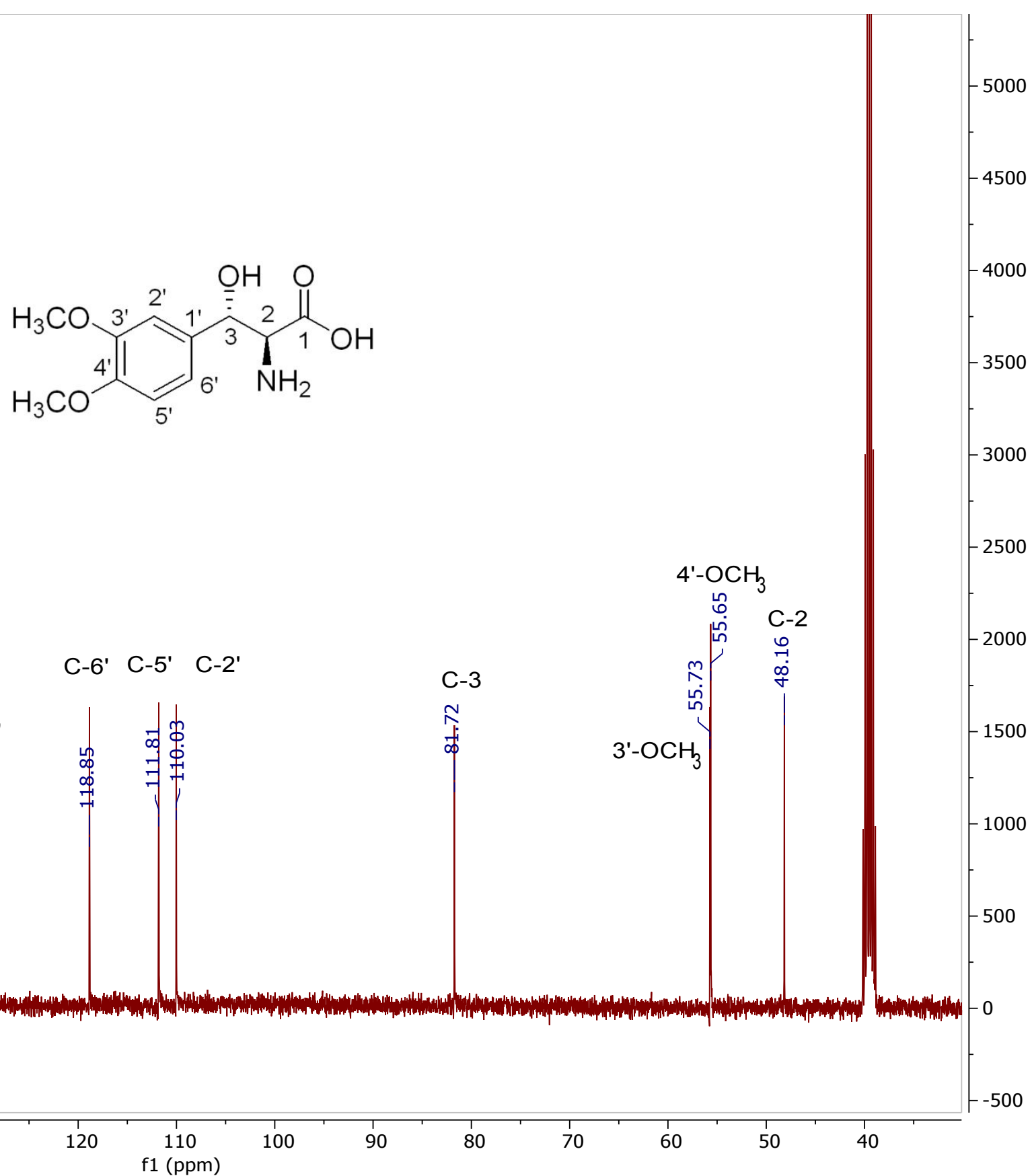

Figure S42. ${ }^{13} \mathrm{CNMR}$ (DMSO, $100 \mathrm{MHz}$ ) of (3S)-hydroxy-3',4'-dimethoxy-L-phenylalanine (5) 


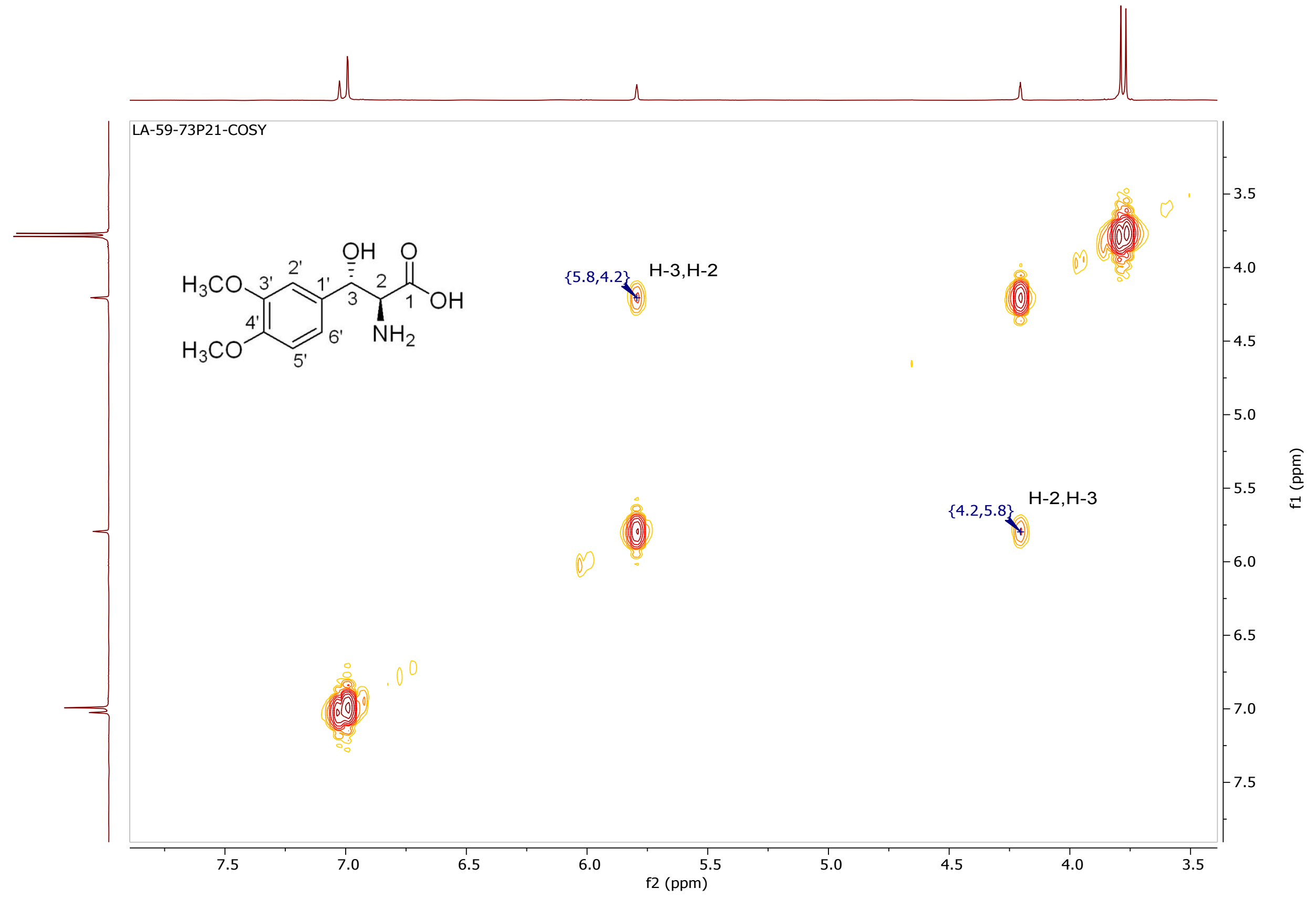

Figure S43. COSY (DMSO, 400 MHz) of (3S)-hydroxy-3',4'-dimethoxy-L-phenylalanine (5) 


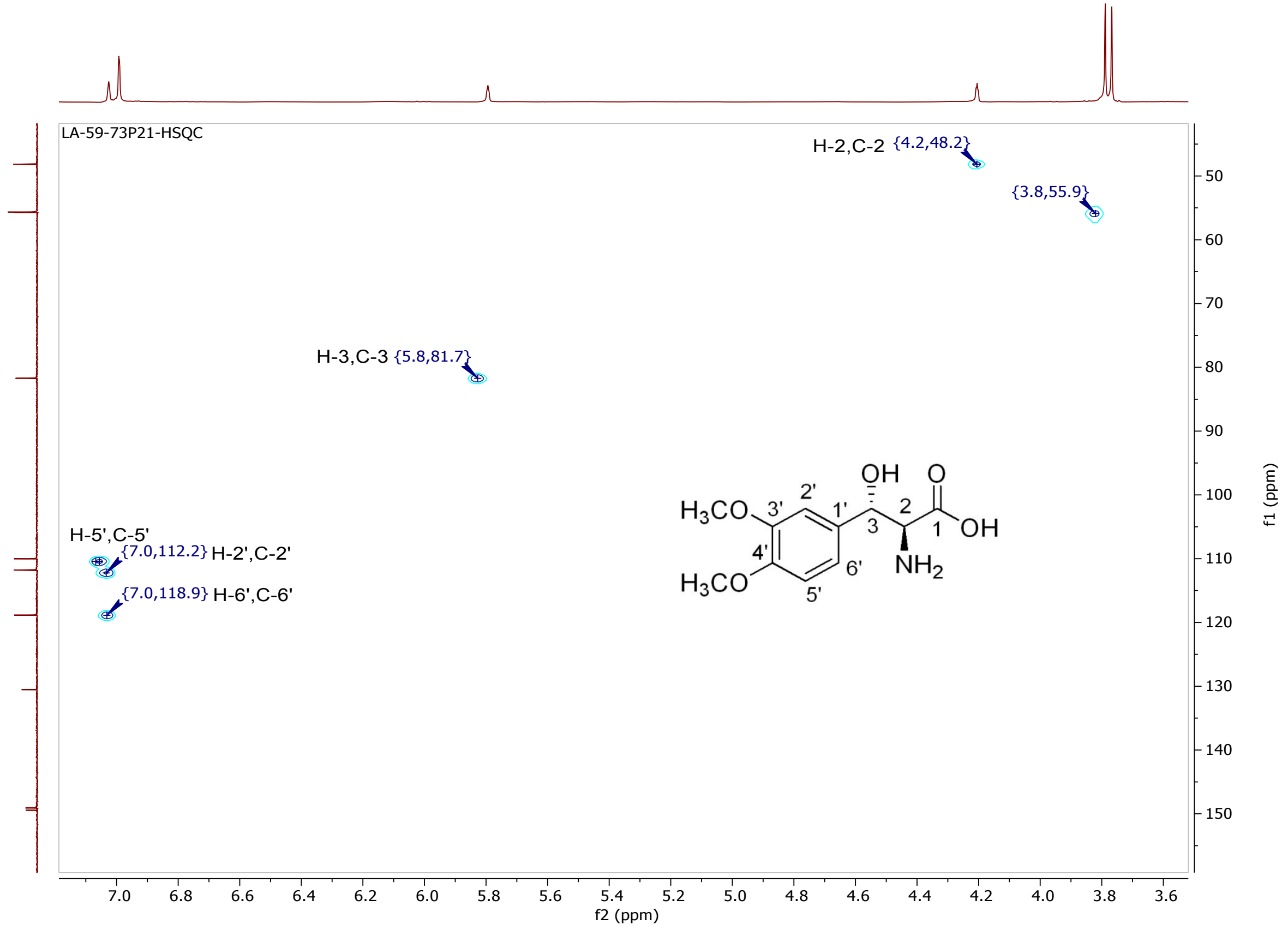

Figure S44. HSQC (DMSO, $400 \mathrm{MHz}$ ) of (3S)-hydroxy-3',4'-dimethoxy-L-phenylalanine (5) 


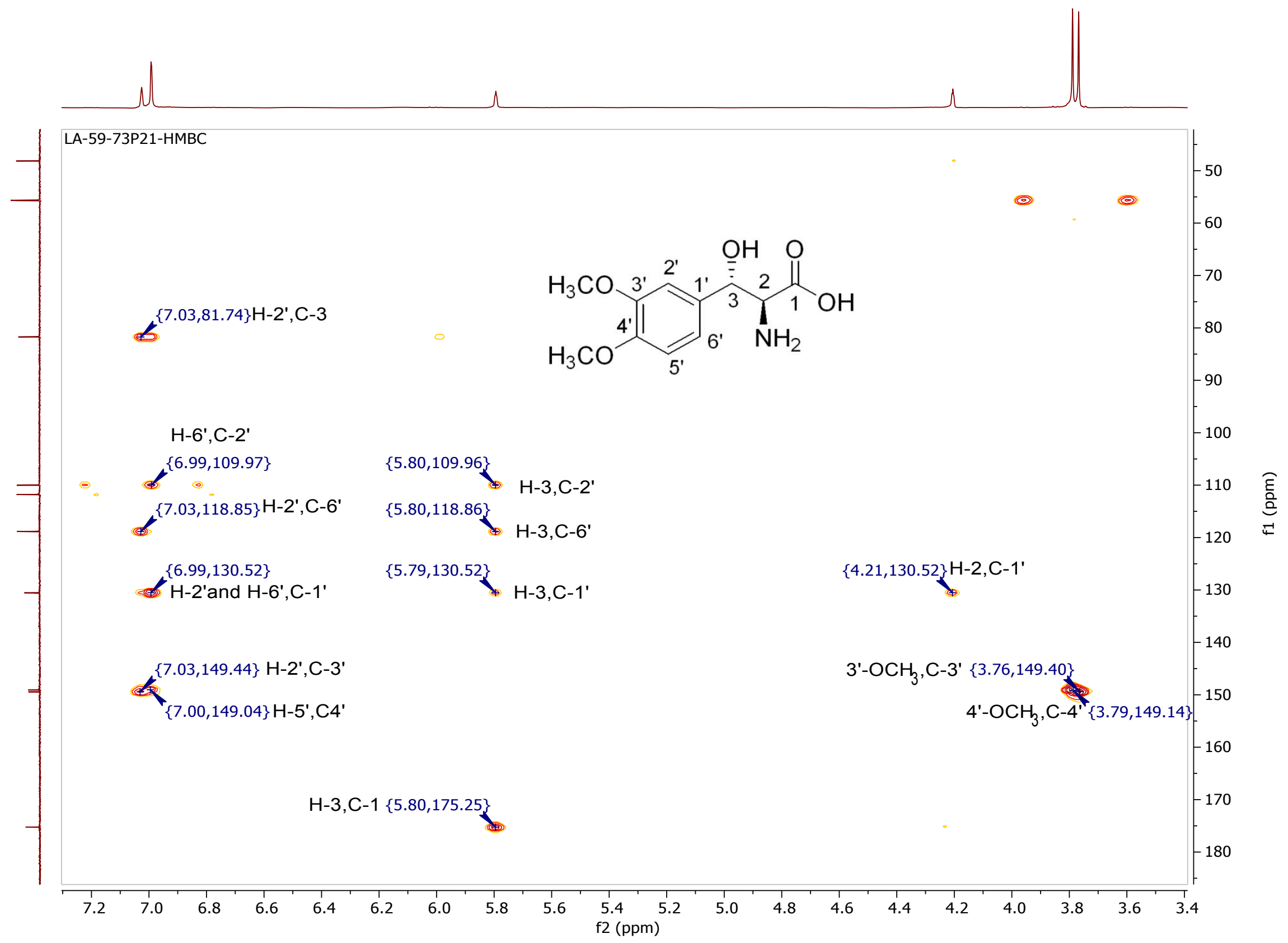

Figure S45. HSQC (DMSO, 400 MHz) of (3S)-hydroxy-3',4'-dimethoxy-L-phenylalanine (5) 